Savannah River Site

High Level Waste Salt Disposition

Systems Engineering Team

HLW Salt Disposition Alternatives Identification

Preconceptual Phase II

Summary Report

WSRC-RP-98-00165

Revision: 2

June 24, 1999

Copy \#: 
HLW Salt Disposition Alternatives Identification Preconceptual Phase II Summary Report 


\section{REVISION SUMMARY}

$\underline{\text { Rev. No. }} \underline{\text { Rev. Date }}$

$0 \quad 6 / 27 / 98 \quad$ N/A

$19 / 9 / 98$

\section{$\underline{\text { Affected Sections }}$}

1.0

Table 9

14.1

Figure 5

Table 11

Various

$6 / 24 / 99$

All

\section{Description of Revision}

Initial Issue

Expanded and clarified Executive Summary \& updated Figure 1 to reflect application of uncertainty

Corrected Figure 2 reference

Clarified role of Safety and Regulatory Engineer

Added reference to Figure 4

Added description of assumptions, results summary and Tables 3 thru 6 . Renumbered other tables accordingly

Corrected error in Alt 7 and 12, 6.0 \& Total Values

Added reference to new Figure 5

Added new Figure 5 reflect risk / selection approach

Revised to show correct formula for ferrocynides and added alternate precipitate of sodium nickel ferrocyanide

Clarified reference to later Phase III activities

Expanded and clarified Phase III approach

Renumbered Figure 5

Clarified Phase III

Revised acronym listing to reflect acronyms within text and removed acronym definitions for acronyms previously defined (various pages) Consistently titled Small Tank TPB

Non WSRC references removed to allow for STI review. 


\section{TABLE OF CONTENTS}

$\underline{\text { Section }}$

$\underline{\text { Page }}$

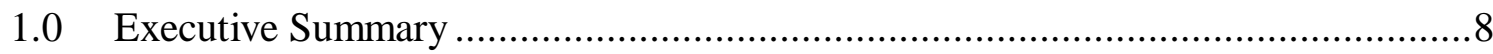

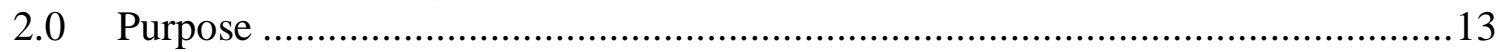

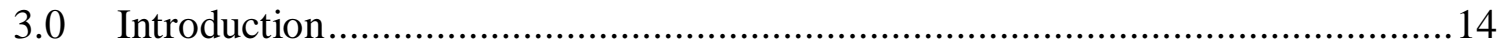

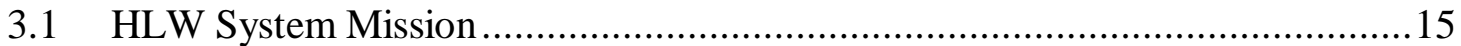

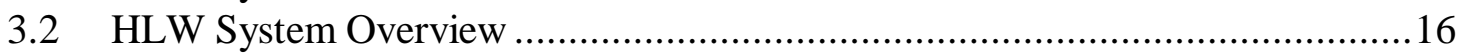

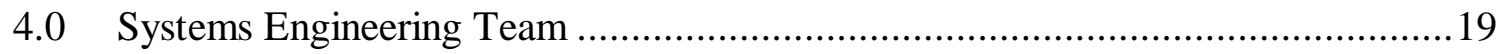

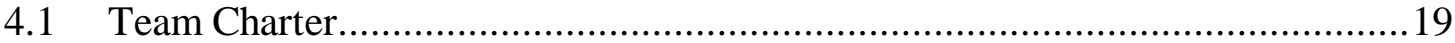

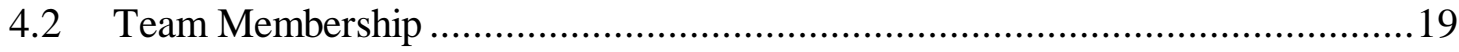

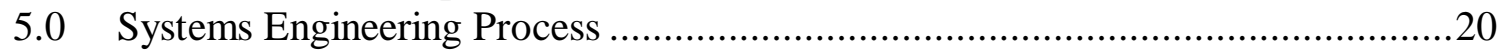

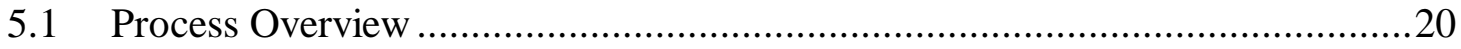

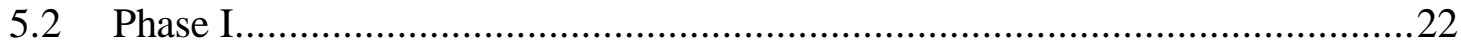

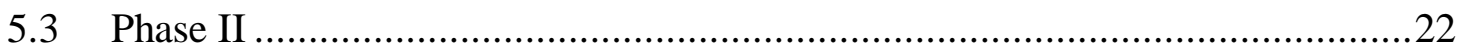

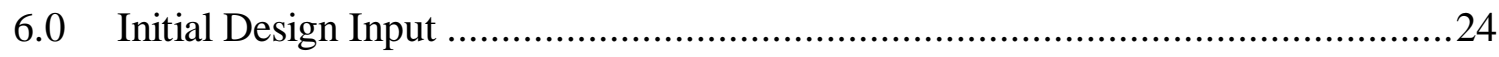

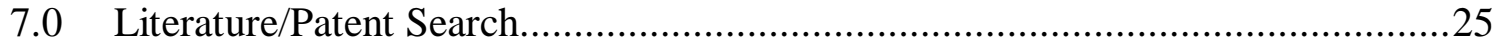

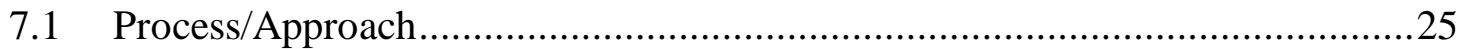

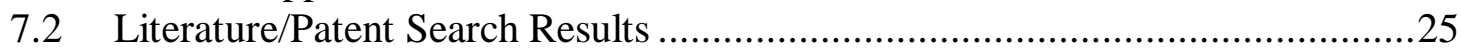

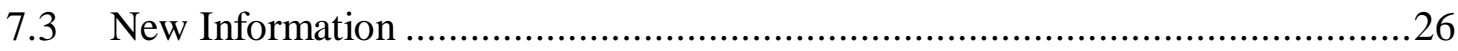

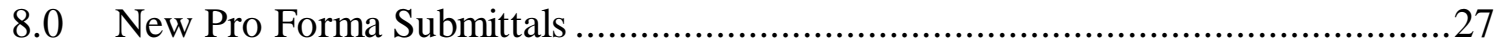

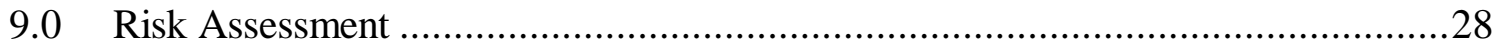

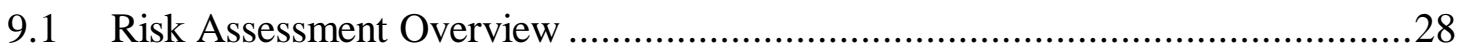

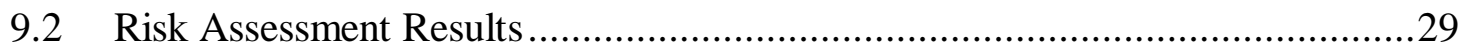

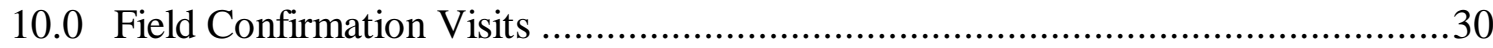

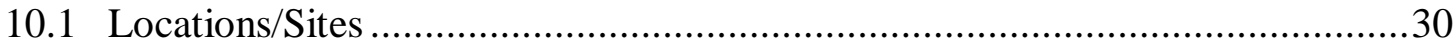

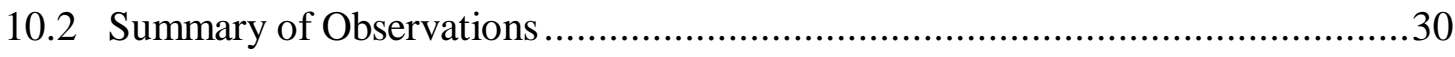

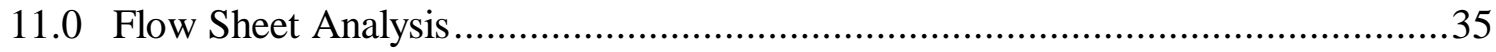

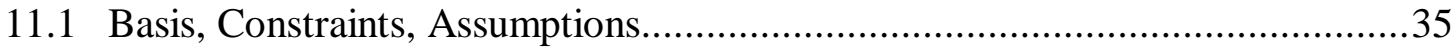

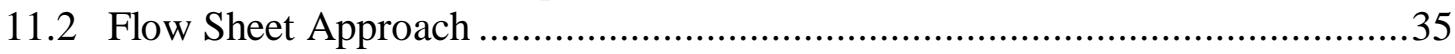

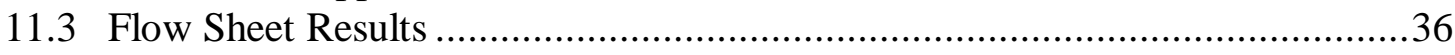

12.0 Preliminary Life Cycle Cost Comparison ...........................................................43

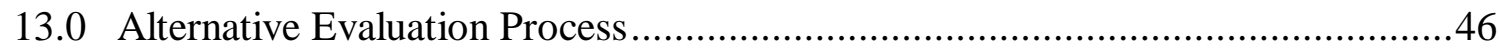

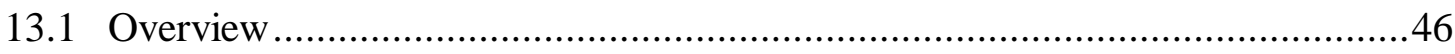

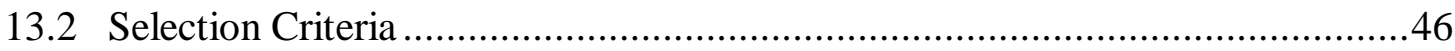

13.3 Utility Function Definition ………............................................................49

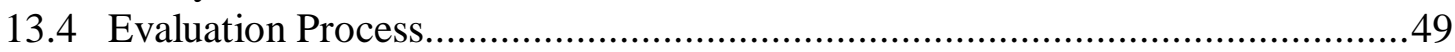

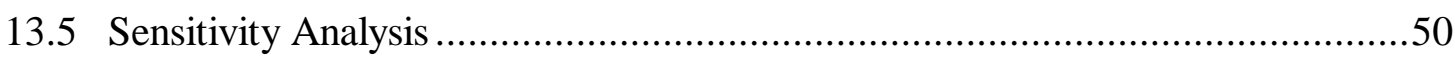

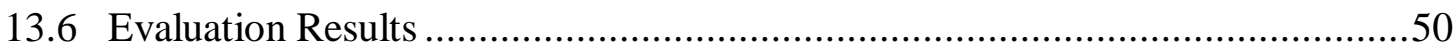

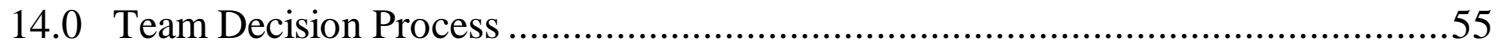

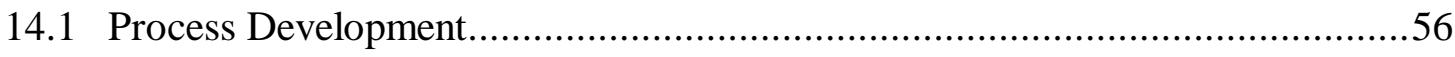




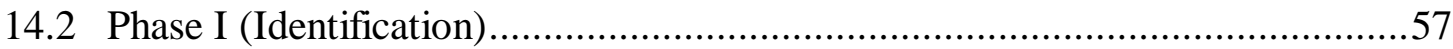

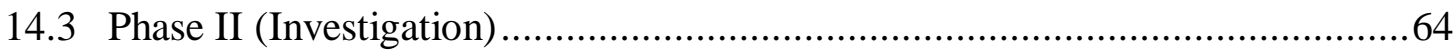

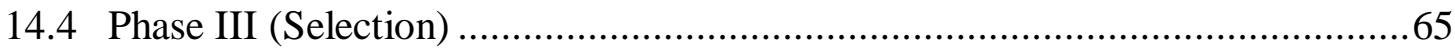

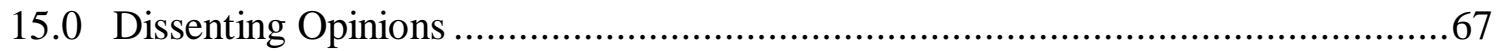

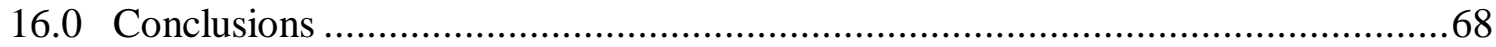

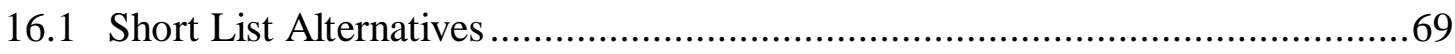

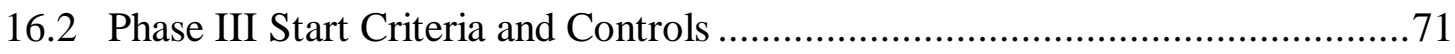

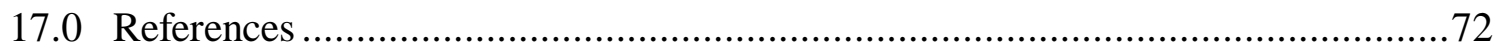

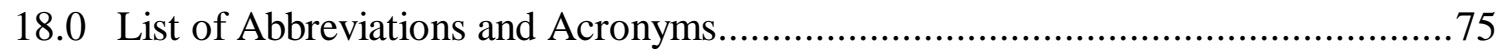




\section{TABLE OF CONTENTS (continued)}

$\underline{\text { Tables }} \quad \underline{\text { Page }}$

Number

Table 1: Risk Assessment Overview

Table 2: Field Confirmation Trips.

Table 3: Raw Materials Consumed

Table 4: Waste Processed .................................................................................... 38

Table 5: Products

Table 6: Environmental Releases.

Table 7: Preliminary Life Cycle Cost Comparison

Table 8: Titles, Definitions, \& Weights of Evaluation Criteria Utilized in Phase II47

Table 9: Weighted Evaluation Scores for the Initial List Alternatives

Table 10: Level 1 Weighted Scores for Alternative Variations .............................53

Table 11: DOE Complex Technology Review Comparison ...................................63

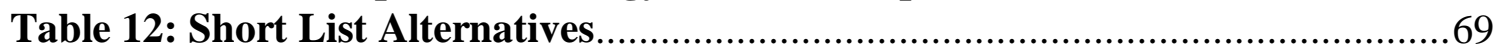

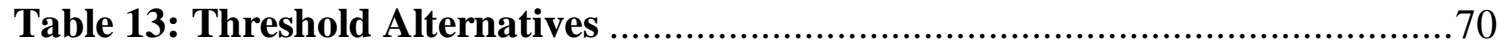




\section{TABLE OF CONTENTS (continued)}

$\underline{\text { Figures }}$

Page

Number

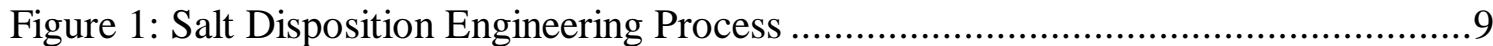

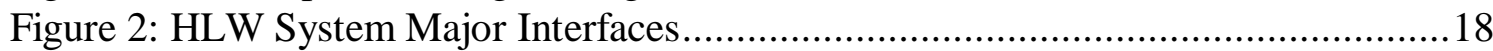

Figure 3: Relationship of the Systems Engineering Process and Project Life Cycle ........21

Figure 4: Functional and Universal Models .............................................................24

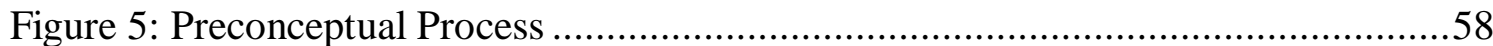

Figure 6: Down Select Process ...............................................................................68 


\subsection{Executive Summary}

The High Level Waste (HLW) Salt Disposition Systems Engineering Team (Team) was formed on March 13, 1998, under the sponsorship of the Westinghouse Savannah River Company (WSRC) High Level Waste Division Vice President and General Manager. The Team is chartered to identify options, evaluate alternatives and recommend a preferred alternative(s) for processing HLW salt to a permitted waste form. This requirement arises because the existing In-Tank Precipitation (ITP) process, as currently configured, cannot simultaneously meet the HLW production and Authorization Basis safety requirements.

During the past two years, reaction mechanisms and kinetics studies of ITP have been underway in response to the Defense Nuclear Facilities Safety Board (DNFSB) Recommendation 96-1 (Reference 1). These studies provide a benchmark for scientific maturity to be used in the Team decision making process.

The Team is comprised of experts from WSRC and its partners, with outside consultant support from academia, National Laboratories and the Department of Energy (DOE) complex. Team membership and position attributes are identified in the HLW-OVP-980020, "HLW Salt Disposition Systems Engineering Team Charter" (Reference 2).

The Charter identifies three phases in the achievement of the Team's mission:

Phase I: Problem definition, ideas generation and coarse screening to create an "Initial List of alternatives (See Figure 1 - Identification).

Phase II: Preliminary risk analysis and engineering flowsheet evaluation to downselect to a "Short List" of alternatives (Figure 1 - Investigation).

Phase III: Detailed evaluation and analysis of the Short List, including preparation of life cycle cost estimates, to downselect to a preferred alternative (Figure 1 -Selection).

This report documents the process adopted and the results obtained from the first two phases. 
Figure 1: Salt Disposition Engineering Process

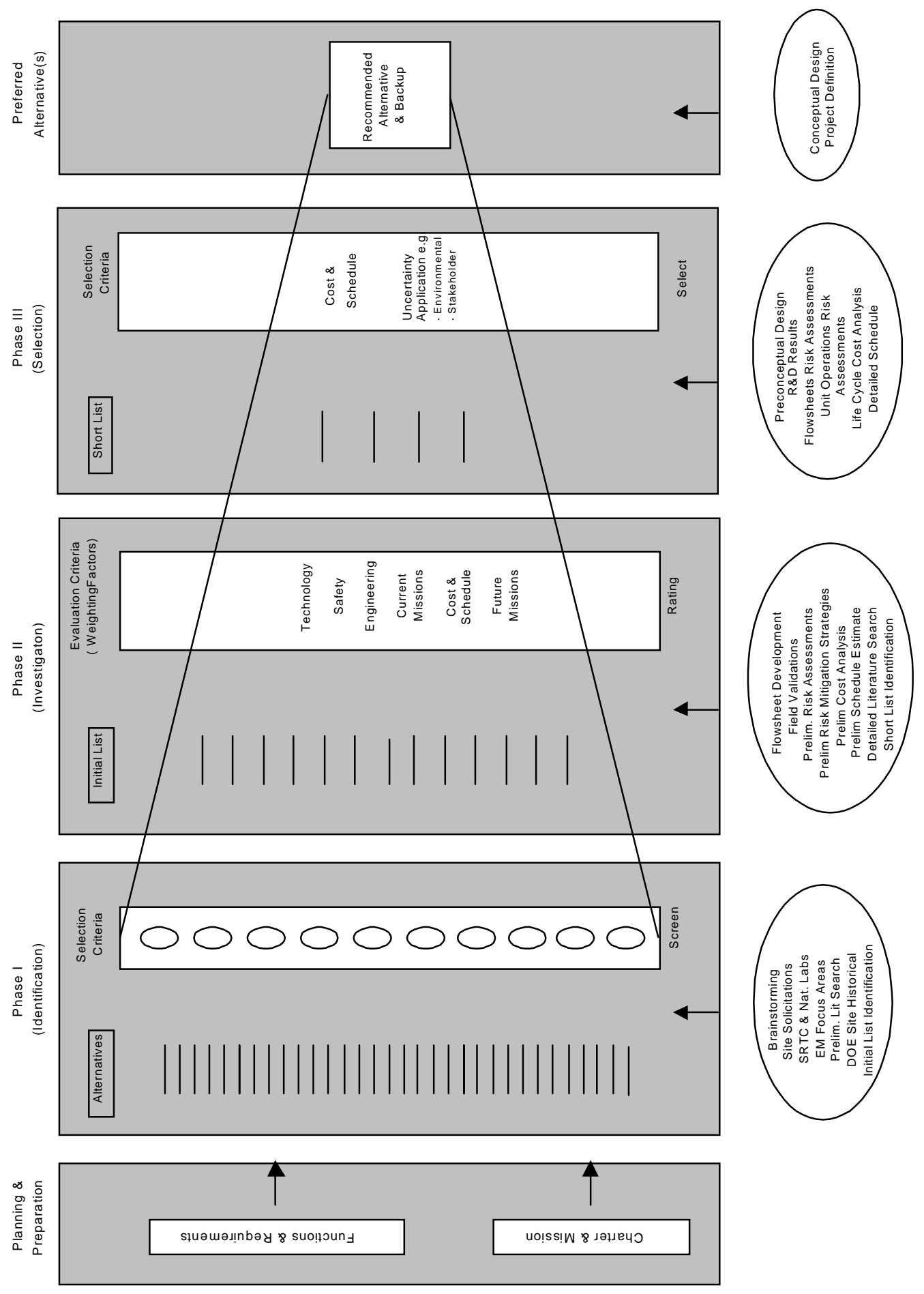


A number of different approaches were used to identify alternative processes to meet the production and safety requirements for salt disposition. Tapping the Savannah River Technology Center (SRTC) technologies and the Operations and Engineering expertise throughout the Savannah River Site (SRS) via "Pro-Forma" (Reference 8) along with formal brainstorming with internal/external stakeholders and selected technical experts throughout the DOE complex maximized the capture of technologies for evaluation. This was supplemented by historical reviews and literature surveys. Facilities within the DOE complex and other companies with chemical processing experience, (e.g. Corps of Engineers, Oak Ridge National Laboratory (ORNL), and British Nuclear Fuels plc ${ }^{1}$ (BNFL)), were accessed for ideas as well. Ideas were submitted on forms called Pro-Forma sheets.

The resulting list of approximately 130 submittals was evaluated against a set of minimum screening criteria that included scientific maturity, engineering maturity, implementation feasibility, safety, licensability, and feasibility of permitting the final waste form. Alternatives were either accepted as written, modified by combination or addition, or dismissed.

The Phase I ranking was performed within technology categories in order to focus on the alternatives with the highest potential for success. The result of the exercise was an Initial List of 18 alternatives selected for further evaluation, which were grouped in the following categories: Crystallization, Electrochemical, Elutable Ion Exchange, Non-elutable Ion Exchange, Organic Precipitation/ Modify ITP, Organic Precipitation/ New Facility, Solvent Extraction, Vitrification, and Miscellaneous.

As a result of the historical literature and patent review of cesium removal technologies, (Reference 3), one additional Pro-Forma was submitted. This new Pro-Forma was reviewed along with 15 other submittals received after the Phase I evaluation. No new alternatives were identified in the 16 post-Phase I submittals although some were carried forward as variations on the "Initial List" alternatives. New Pro-Formas will continue to be accepted for review until the Team submits a preferred alternative(s) recommendation at the conclusion of Phase III.

One of the building blocks in the Systems Engineering process to facilitate selection of the Short List of alternatives in Phase II was the application of a preliminary risk assessment of the Initial List alternatives. Approximately 400 risks of varying significance were identified during the assessment. In order to validate the risks identified for the candidate alternatives, field confirmation trips were taken to sites representing the technologies identified. The site visits provided valuable technical information and broadly confirmed the assessment process applied and preliminary risk assessments identified by the Team.

${ }^{1}$ plc - public limited company

Following the preliminary risk assessment, a review was performed to ensure consistent identification of risk. For those risks categorized as high a strategy was determined to 
handle the risk, if possible, and the corresponding risk value was revised to reflect this change.

To provide a technical basis for the selection process, flowsheets were developed for each Initial List alternative. The alternative processes were modeled to provide anticipated material balances, waste processing rates, emission levels, chemical adjustments, Defense Waste Processing Facility (DWPF) canister production, and saltstone production. Flowsheets were presented on Process Flow Diagrams for Phase II.

Weighted evaluation criteria and supporting utility functions were developed to assist in the process of establishing the "Short List" of alternatives. The Team used information from the preliminary risk assessment, off-site trips, preliminary life cycle cost estimates, and flowsheet analysis to score each alternative against the following weighted evaluation criteria:

- Technology

- Current Mission Interfaces

- Future Mission Interfaces

- Regulatory/ISMS $/$ Environmental

- Engineering (Design)

- Cost/Schedule

A structured process (Multi-Attribute Utility Analysis and Analytical Hierarchy Process) was utilized by the Team to perform the evaluation. The weighting factors selected for Phase II ensured that Science, Engineering, and Safety attributes were most important at this step. The Team feels that all alternatives selected for the Short List can be implemented in the field. Phase III will concentrate on cost, schedule and application of uncertainty.

The Team evaluation resulted in the following Short List:

- Direct Disposal as Grout

- Small Tank TPB

- Non-elutable Ion Exchange (glass/ceramic waste form)

- Caustic Side Solvent Extraction

${ }^{1}$ ISMS - Integrated Safety Management System 
Direct Disposal as Grout was chosen for continued evaluation due to simplicity of the process, high throughput capability, and extensive operational experience while understanding that the Regulatory impact due to permanent disposal of the Class $\mathrm{C}$ grout at Savannah River Site may be substantial. Small Tank TPB was chosen due to the level of technology understanding based on the chemistry testing over the past two years, its simple unit operations, and compatibility with existing infrastructure.

Several of the crystalline silicotitanate (CST) and zeolite non-elutable ion exchange options ranked well due to the stability of the separation media, high levels of pilot and production nuclear experience, and compatibility with the SRS salt waste streams. The Team selected CST with DWPF vitrification as the focus for short list analysis based on its flexibility. Caustic Side Solvent Extraction also ranked well as compared to the other Initial List alternatives due to significant, positive operating experience using solvent extraction on and off-site, no impact on glass formulation, and high level of the engineering maturity of the extraction unit operations. 


\section{$\underline{\text { 2.0 } \quad \text { Purpose }}$}

The purpose of the report is to summarize the process used to identify the Short List alternatives that will be evaluated during Phase III and to document the results of the selection process. The Phase III evaluation will result in the determination of the preferred alternative(s) to be used for final disposition of the HLW salt to a permitted waste form. 


\subsection{Introduction}

The High Level Waste System is a set of seven interconnected processes (Figure 2) operated by the High Level Waste Division and Solid Waste Division. These processes function as one large treatment plant that receives, stores, and treats high-level wastes at SRS and converts these wastes into forms suitable for final disposal. The three major permitted disposal forms are borosilicate glass, planned for disposal at a Federal Repository; saltstone grout, pumped to vaults for disposal in the Saltstone Facility at SRS; and treated water effluent, released to the environment.

These processes currently include:

1) High-Level Waste Storage and Evaporation (F and H Tank Farms)

2) Salt Processing (In-Tank Precipitation and Late Wash Facilities)

3) Sludge Processing (Extended Sludge Processing Facility)

4) Vitrification (Defense Waste Processing Facility)

5) Wastewater Treatment (Effluent Treatment Facility)

6) Solidification (Saltstone Facility)

7) Organic Destruction (Consolidated Incineration Facility)

The F and H Tank Farm Facilities, Extended Sludge Processing Facility, Defense Waste Processing Facility, Effluent Treatment Facility, and the Consolidated Incineration Facility are operational. The In-Tank Precipitation Facility operations are limited to safe storage and transfer of materials. The Late Wash Facility has been tested and is in a dry lay-up status. The Saltstone Facility will be placed in a partial lay-up by the end of Fiscal Year 1998. The ITP Facility initiated radioactive operation in Tank 48H in September of 1995. During pump operation in December of 1995, benzene evolved from Tank $48 \mathrm{H}$ at higher rates than expected though the operational safety limit was never approached. The benzene was generated as a byproduct of the process from the catalytic decomposition of sodium tetraphenylborate (NaTPB).

In August 1996, the DNFSB issued Recommendation 96-1. The DNFSB recommended that operating and testing in the ITP Facility not proceed without an improved understanding of the mechanisms of benzene generation, retention, and release. Chemistry studies were undertaken in order to explain the benzene generation, retention, and release mechanisms and respond to the DNFSB Recommendation 96-1. These studies indicated that production goals and safety requirements for processing of HLW could not be accomplished in the ITP Facility as configured. This resulted in a WSRC recommendation to the Department of Energy in January 1998 to conduct a systems evaluation of salt disposition options and to recommend the preferred alternative. The salt will remain in storage until an alternative salt pre-treatment process is identified and implemented. Alternative processes will be evaluated throughout Fiscal Year 1998. 
In March 1998, a team was selected to perform a structured Systems Engineering analysis of options for salt disposition. Guidance for the Team is documented in the charter. The task of salt disposition evaluation is broad based in technical scope and is not limited to any single process. Precipitation methods, ion exchange processes, other chemical or mechanical separation techniques, direct vitrification/grout options, or combinations of these options are being considered.

Although the process selected will be specifically for HLW salt disposition, the team must address the system impact for all HLW facilities. Additionally, the selected alternative must interface safely and efficiently with the remainder of processing facilities outside of HLW. Timeliness of the selection of alternatives is key to support tank farm space/water inventory management and the Federal Facility Agreement (FFA) for tank closure.

\section{$\underline{\text { 3.1 HLW System Mission }}$}

The mission of the HLW System is to receive and store SRS high-level wastes in a safe and environmentally sound manner and to convert these wastes into forms suitable for final disposal. The planned forms are: 1) borosilicate glass to be sent to a Federal Repository, 2) saltstone to be disposed of on site, and 3) treated wastewater to be released to the environment. Also, the storage tanks and facilities used to process the high-level waste must be left in a state such that they can be decommissioned and closed in a cost-effective manner and in accordance with appropriate regulations and regulatory agreements.

The FFA requires removal of the waste from the high-level waste tanks to resolve several safety and regulatory concerns. Tanks have leaked observable quantities of waste from primary to secondary containment. Other tanks have known penetrations above the liquid level, although no waste has been observed to leak through these penetrations. The "old style" tanks do not meet the Environmental Protection Agency (EPA) secondary containment standards for storage of hazardous waste (effective January 12, 1987).

The FFA for Savannah River Site (SRS) addresses the DOE committed schedule for removing the wastes from the high-level waste tanks.

All high-level wastes in storage at SRS are Land Disposal Restricted (LDR) wastes, which are prohibited from permanent storage. Since the planned processing of these wastes will require considerable time and therefore continued storage of the waste, DOE has entered into a compliance agreement with the EPA and South Carolina Department of Health and Environmental Control (SCDHEC). This compliance agreement is implemented through the Site Treatment Plan (STP) which requires processing of all the high-level waste at SRS according to a negotiated schedule. 
The issue impacting the HLW overall mission is that the currently configured In-Tank Precipitation process cannot simultaneously meet the HLW flowsheet production goals and the safety requirements. WSRC recommended that alternative concepts and technologies be evaluated. The Team was formed and chartered to perform this task. The Mission Need defined for the Team is:

"The SRS HLW salt needs to be immobilized for final disposition in support of environmental protection, safety, and current and planned missions".

\subsection{HLW System Overview}

Figure 2 schematically illustrates the routine flow of wastes through the HLW System. The various processes within the system and external processes are shown in rectangles. The numbered streams identified in italics are the interface streams between the various processes. The discussion below represents the HLW system configuration as of January 1998.

Incoming high-level wastes are received into HLW Storage and Evaporation ( $\mathrm{F}$ and $\mathrm{H}$ Tank Farms) (Stream 1). The function of HLW Storage and Evaporation is to safely concentrate and store these wastes until downstream processes are available for further processing. The decontaminated liquid from the evaporators is sent for Wastewater Treatment at the Effluent Treatment Facility (ETF) (Stream 13).

The insoluble sludges that settle to the bottom of waste receipt tanks in HLW Storage and Evaporation are slurried using hydraulic slurrying techniques and sent to the Extended Sludge Processing (ESP) Facility (Stream 2). In the ESP Facility, sludges high in aluminum are processed to remove some of the insoluble aluminum compounds. All sludges, including those that have been processed to remove aluminum, are washed with water to reduce their soluble salt content. The spent washwater from this process is sent back to HLW Storage and Evaporation (Stream 3). The washed sludge is sent to DWPF for feed pre-treatment and Vitrification (Stream 4).

Saltcake is dissolved using hydraulic slurrying techniques similar to slurrying of sludge. As currently designed, the salt solutions from this operation and other salt solutions from HLW Storage and Evaporation were intended for feed to Salt Processing at the ITP Facility (Stream 5). In the ITP Facility, the salt solution would be processed to remove radionuclides, which are concentrated into an organic precipitate. The decontaminated filtrate would then be sent to Tank 50. The process produces a concentrated organic precipitate, containing most of the radionuclides. This precipitate is washed with water to remove soluble salts.

Some soluble corrosion inhibitors that interfere with DWPF processing must be left in the precipitate after washing because the precipitate is stored in carbon steel tanks, which are 
susceptible to corrosive attack by uninhibited precipitate wastes. The precipitate is transferred to the Late Wash Facility for further washing in stainless steel tanks to reduce the level of soluble corrosion inhibitors to acceptable levels for the DWPF process (Stream 7). The washwater from this process is returned to the ITP Facility to be re-used in the ITP process (Stream 8 ).

The washed precipitate from Late Wash is then sent to the DWPF for vitrification. In the DWPF, the precipitate is catalytically decomposed and separated into two streams: a mildly contaminated organic stream and an aqueous stream containing virtually all of the radionuclides. The mildly contaminated organics are stored at the DWPF and will be transferred to the Consolidated Incineration Facility (CIF) for Organic Destruction (Stream 11). The aqueous stream is combined with the washed sludge from ESP for vitrification.

The washed sludge from ESP (Stream 4) is chemically adjusted in the DWPF to prepare the sludge for feed to the glass melter. As part of this process, mercury is stripped out, purified and sent to mercury receivers (Stream 12). The aqueous product from organic decomposition is added to the chemically adjusted sludge. The mixture is then combined with glass frit and pumped to the glass melter. The glass melter drives off the water and melts the wastes into a borosilicate glass matrix, which is poured into a canister. The canistered glass waste form is placed in interim storage on site, and will eventually be disposed of in a Federal Repository (Stream 9).

The water vapor driven off from the melter along with other aqueous streams generated throughout the DWPF vitrification building are recycled to HLW Storage and Evaporation for processing (Stream 10).

Overheads from the HLW Storage and Evaporation evaporators are combined with overheads from evaporators in the F and H-Area Separations processes and other low-level streams from various waste generators. This mixture of low-level wastes is sent to the ETF (Stream 13).

In the ETF, these low-level wastes are decontaminated by a series of cleaning processes. The decontaminated water effluent is sent to the H-Area outfall and eventually flows to local creeks and the Savannah River (Stream 14). The contaminants removed from the water are concentrated and pumped to Tank 50 (Stream 15).

In Tank 50 the concentrate from the ETF is combined with the decontaminated filtrate from the ITP and pumped to the Saltstone Facility (Stream 6). In the Saltstone Facility, the liquid waste is combined with cement formers and pumped as a wet grout to a vault that is a permitted Landfill (Stream 16). In the vault, the cement formers hydrate and cure, forming a saltstone monolith. The Saltstone Facility vaults will eventually be closed as a landfill. 


\section{HLW System Major Interfaces}

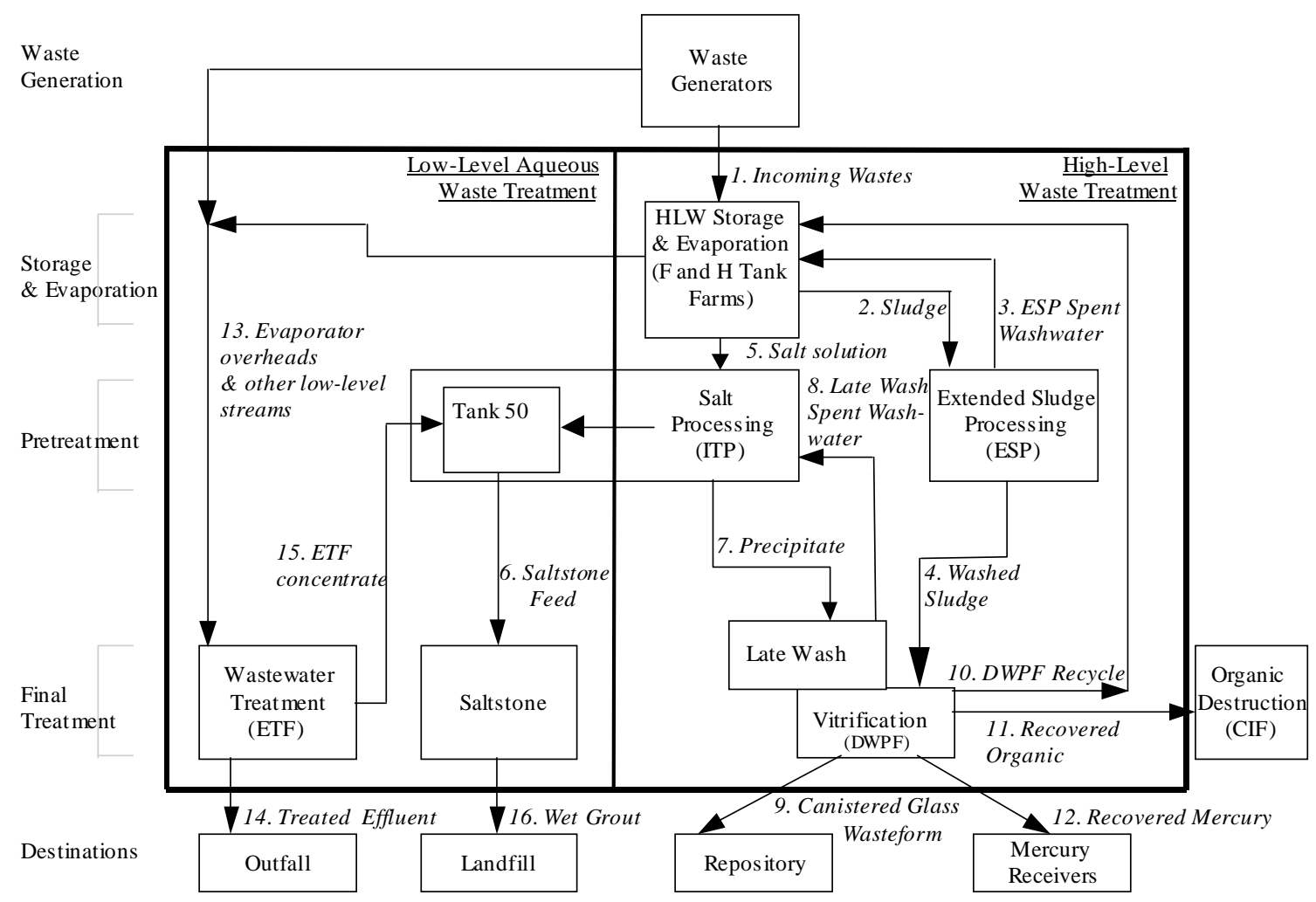

Figure 2: HLW System Major Interfaces 


\subsection{Systems Engineering Team}

The WSRC recommendation to DOE for the evaluation of alternative technologies and/or concepts to the currently configured ITP process resulted in the formation of the SRS High Level Waste Salt Disposition Systems Engineering Team. The Charter and membership of the Team are discussed below.

\subsection{Team Charter}

The Team was chartered on March 13, 1998 (Reference 2). The Charter discusses the Team's objective, the required team membership attributes, the requirement to follow the Systems Engineering approach, and the major deliverables and milestones expected of the Team.

\subsection{Team Membership}

The members of the Team, their role on the Team and company affiliation are shown below:

$\underline{\text { Team Member }}$

S. F. Piccolo

G. E. Abell

J. L. Barnes

E. T. Murphy

(J. D. Carlson - Alternate)

E. L. Cussler, Ph.D.

P. I. Hudson

E. J. Kosiancic

L. M. Papouchado, Ph.D.

K. J. Rueter

J. S. Watson, Ph.D. $\underline{\text { Role }}$

Team Leader

Systems Engineering

Operations

Safety \& Regulatory Eng.

Chemical

Engineering/Academia

Waste Processing

Process Engineering

Consultant

Science/Site Research

Process Engineering

Science/National Lab

Research

\section{Company}

Affiliation*

WSRC

WSRC

WSRC

WSMS

Univ. of Minnesota

BNFL

Independent

Contractor

WSRC

WSRC

ORNL

*WSRC: Westinghouse Savannah River Company

*WSMS: Westinghouse Safety Management Solutions, Inc.

*BNFL: BNFL Savannah River Corporation

*ORNL: Oak Ridge National Laboratory

Additional information, including biographies of team members, is provided in Candidate Selection for the HLW Salt Disposition Systems Engineering Team (Reference 4). 


\subsection{Systems Engineering Process}

The Team developed WSRC-RP-98-00163, "Systems Engineering Management Plan for Development of Alternatives to Process and Dispose of High Level Waste Salt" (Reference 5). The Systems Engineering Management Plan (SEMP) outlines the steps and sequences for a systematic engineering process utilized by the Team in identifying and selecting the preferred alternative(s). In essence, the Systems Engineering approach mandates that the problem is defined, a mission is created to solve the problem, and a definition of what the solution must do (functions) and how well it must do it (requirements) be addressed (Reference 6 and 7) before selecting solutions.

Use of the Systems Engineering approach, to identify a preferred alternative(s) to the currently configured ITP process, is required by the Team Charter.

\subsection{Process Overview}

The Systems Engineering approach is a top down process and is recognized as a viable technical management approach to define and control the development of complex technical programs/systems with many uncertainties, risks, interfaces, and elements. The main goal of the Systems Engineering approach is to deliver an end product that meets cost, schedule, and technical requirements while minimizing the environmental, safety, and health risks. The use of this approach will enable the Team to meet its intended goal. The major process steps are discussed below and are illustrated in Figure 3.

- Definition and Development

Definition and development represents the logical sequence of activities and decisions designed to transform facility operational needs and customer requirements into a preferred system concept, design, and its related performance parameters to meet the Mission Need. Definition and development steps include:

- Mission Definition and Analysis

- Functions and Requirements

- Alternative Designs, Evaluation, and Selection

- Verification and Validation

- Technical Program Planning and Control

Technical program planning and control encompasses management activities to effectively plan and control the activities to meet program technical requirements. 
Revision: 2

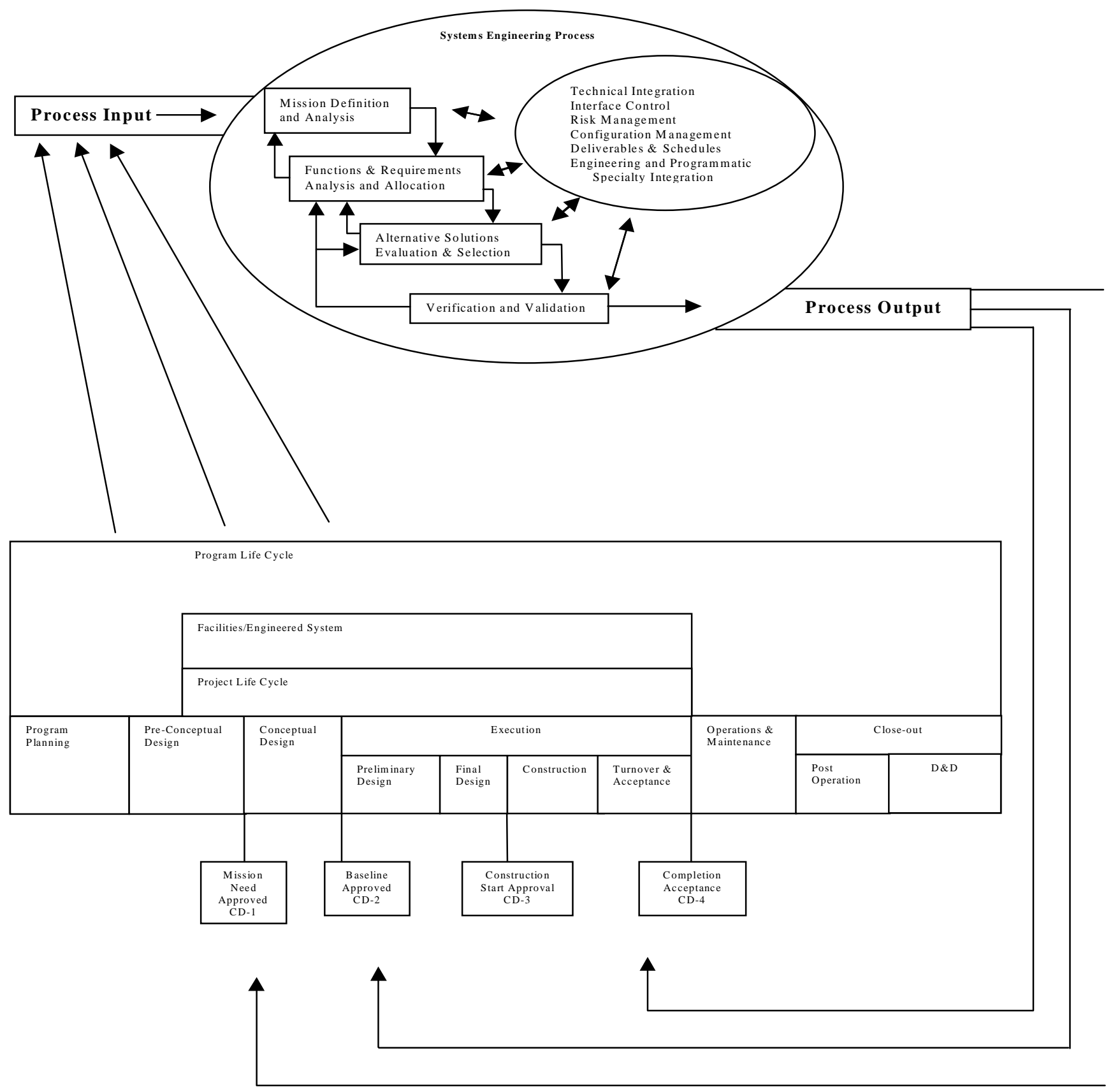


These steps include:

- Technical Integration

- Interface Control

- Risk Management (technical, programmatic, life cycle cost)

- Configuration Management

- Deliverables and Schedules

- Engineering and Programmatic Specialty Integration

- This integration is the timely and appropriate application of engineering efforts and specialty disciplines such as chemical processing, reliability, maintainability, life cycle cost, human factors, safeguards and security, environmental, authorization basis/safety, health, etc. This type of integration ensures that all aspects of the project are reviewed from the specialized areas important to project formulation, implementation, and operation.

\section{$\underline{5.2 \quad \text { Phase I }}$}

Phase I of the Systems Engineering approach for the selection of the In-Tank Precipitation alternative began with the selection of the Team and issuance of the Team Charter. The Team completed the following Systems Engineering process steps in Phase I:

- Problem Definition (Reference 7)

- Mission Definition and Analysis (Reference 7)

- Systems Engineering Management Plan (Reference 5)

- Functions and Requirements (Reference 7)

- Initial Alternative Evaluation and Selection (Reference 8)

The resultant output from Phase I was the downselect of approximately 130 Pro-Forma submittals to 18 alternatives placed on the Initial List for further evaluation in Phase II.

\section{$\underline{5.3 \quad \text { Phase II }}$}

Phase II of the Systems Engineering approach continued the disciplined analysis of the 18 Initial List alternatives to reach a Short List of alternatives that will be analyzed in more detail during Phase III. The Phase III output will be the recommendation of a preferred alternative(s) for the disposition of the HLW salt. 
The Team performed the following Systems Engineering process steps:

- Preliminary Risk Assessment of the Initial List (Reference 9)

- Flowsheet Analysis (Technical Integration) (Reference 12)

- Preliminary Life Cycle Cost Comparison (Reference 11)

- Definition and Weighting of Evaluation Criteria and Utility Functions (Reference 10)

- Sensitivity Analysis (Reference 28)

- Selection of a Short List (This report)

The Systems Engineering approach in Phase III will continue to be used to identify a preferred alternative(s) to the currently configured ITP process that meets cost, schedule, and technical requirements while minimizing the environmental, safety, and health risks. 


\section{$\underline{6.0 \quad \text { Initial Design Input }}$}

The HLW Salt Disposition Team developed the necessary and sufficient Level 1 and 2 functions and requirements that potential alternatives must meet. These functions and requirements were generated from a Problem Definition Statement and Mission Need Declaration. In addition, the Team identified the external interfaces with which the alternative solutions would interface. Finally, the Team developed a "Functional Model" and a "Universal Model" which envelop all potential alternatives (Figure 4).

HLW SALT DISPOSITION SYSTEM ENGINEERING TEAM MODEL
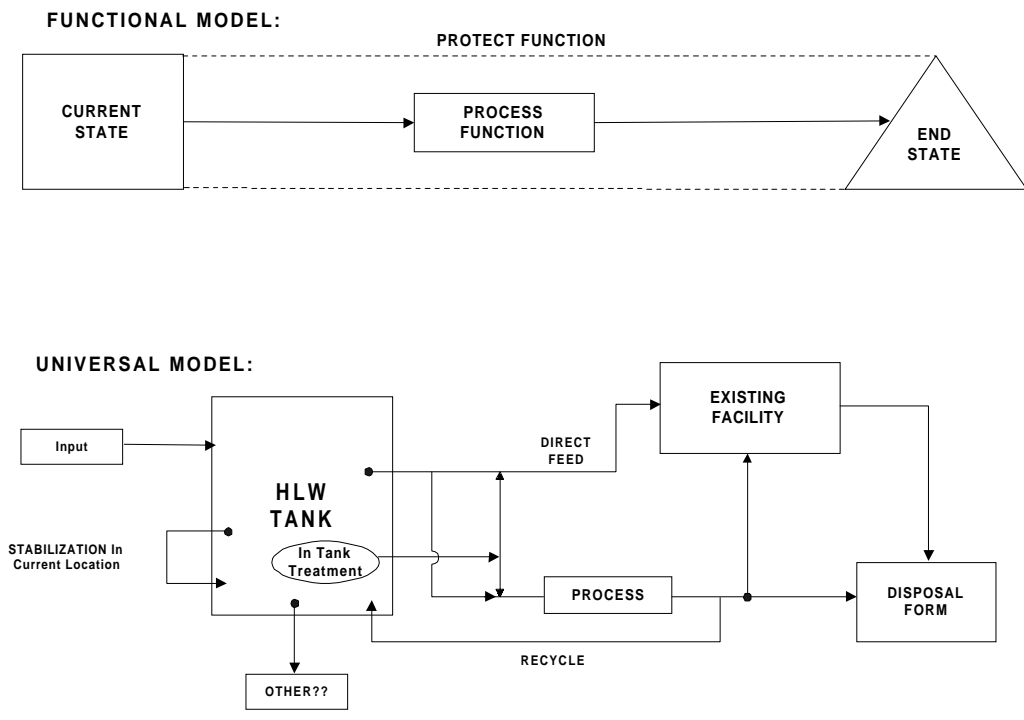

Figure 4: Functional and Universal Models

These models were used to initiate thought on alternatives to the In-Tank Precipitation process while still ensuring compliance with the functions and requirements.

The information discussed above is considered design input and resides in the "Preconceptual - Phase I Initial Design Input" document (Reference 7). 


\subsection{Literature/Patent Search}

As a means to ensure that the alternative identification process captured a sufficiently wide range of options, a historical literature review of worldwide cesium removal technologies was performed.

\subsection{Process/Approach}

A team comprised of personnel from the SRTC, Oak Ridge National Laboratory (ORNL), and Pacific Northwest National Laboratory (PNNL) performed a literature and patent search for worldwide cesium removal technologies. The search included ten databases, personal contacts, as well as libraries at SRTC, ORNL, PNNL, and the University of Tennessee. The search was conducted utilizing the search patterns of cesium removal, cesium separation, and associated separation processes and technologies. The resulting list of over 1700 references to cesium removal was categorized into 16 process technologies (see Section 7.2) for ease of information review (Reference 3). The technology was not reviewed for viability by the literature search team; it was objectively presented in the report generated to identify the results.

Following the search, SRTC personnel were tasked to review the process technologies against the original Pro-Forma submittals to ensure that the 16 process technologies were adequately considered during the downselect process per the Position Paper on Identifying Alternatives to the In-Tank Precipitation Process (Reference 34).

\subsection{Literature/Patent Search Results}

The search resulted in over 1700 literature and patent references for cesium removal. The source documents were identified in the United States and 37 other countries.

Of the 1700 references, ion exchange, solvent extraction, adsorption, and precipitation technologies represented over 90\%. The references were grouped into the following 16 process technologies:

- Adsorption

- Biological Methods

- Centrifugation

- Chromatography

- Crystallization

- Electrochemical

- Evaporation

- Extraction

- Filtration

- Flotation 
Process Technologies (continued)

- Ion Exchange

- Leaching

- Magnetic

- Nanofiltration-complexation

- Precipitation

- Pyrochemical

\subsection{New Information}

ORNL, PNNL, and SRTC reviewed the findings against the original list of alternatives and determined that one Pro-Forma submittal was needed to capture a unique variation. It was expected that a very low number of submittals would result from the literature and patent search due to the inclusion of subject matter experts and reviews of prior literature searches during the original Pro-Forma submittals. This review demonstrated that the Pro-Forma process adequately captured the breadth of technologies for cesium removal.

Additional information can be found in SRT-WPT-98-008, "Evaluation of Potential Cesium Removal Technologies (U)" (Reference 13). 


\section{$\underline{\text { 8.0 New Pro Forma Submittals }}$}

The initial request for alternative ideas for salt disposition resulted in approximately 130 submittals. These submittals were evaluated during Phase I and an Initial List of 18 alternatives was identified from the original list. The Initial List and the activities leading to its creation are described in WSRC-RP-98-00162, "HLW Salt Disposition Alternatives Identification Preconceptual Phase I Summary" (Reference 14). During Phase II, these alternatives have been better defined and further investigated to determine the most viable alternatives to be evaluated in Phase III. Additional Pro-Forma submittals originating from literature searches and professional and commercial inquiries may continue to be received in Phase III up to the recommendation of the preferred alternative(s). These new Pro-Formas will be reviewed against the same criteria and applying the same process used to determine the Initial List and Short List of alternatives.

Sixteen new Pro-Forma submittals were evaluated during Phase II. The new submittals included twelve employee-generated Pro-Formas, three submittals from off-site subject matter experts, and one submittal generated from the literature search described in Section 7.0. No new alternatives were identified from the new Pro-Forma submittals. Nine of the submittals were determined to be new variations on Initial List alternatives and were added to the flagship alternative. Two submittals fell within the existing Initial List alternatives. The remaining five Pro-Forma submittals were rejected because they did not meet the initial screening criteria.

Additional information on the disposition of the new Pro-Formas as well as a copy of the submittal can be found in HLW-SDT-980014, "Position Paper on Dispositioning of ProFormas Received During Phase II" (Reference 15). 


\subsection{Risk Assessment}

The identification and quantification of risk is integral to the Systems Engineering process. General process information and uncertainties are discussed during the risk assessment. A review of each alternative was performed by the Team to identify potential risks associated with implementation of the alternative process. This preliminary risk assessment provided key information to the downselect process to reach the Short List options for HLW salt disposition.

\subsection{Risk Assessment Overview}

The Team performed a preliminary risk assessment to determine risk associated with the candidate alternatives. Risk was defined as the product of the probability of a postulated occurrence and the consequence of that occurrence. Values for probability and consequence are defined in HLW-SDT-980004, "Position Paper on the Determination of Risk and Risk Handling Strategies for the Initial List Alternatives" (Reference 16).

Following the preliminary risk assessment, the Team performed a review of preliminary risk data to ensure consistency in risk assignment. This review included verification of uniformity, risk statement consistency, inclusiveness, completeness, and elimination of "double-counting" the same risk.

At the conclusion of the consistency review, a threshold value was set to define high risk. High risk was defined as a risk value of 0.3 or higher. This value was chosen to ensure that risks with probability of "likely" and consequence of "significant" were included in the next stage of evaluation. The subsequent evaluation determined strategies to handle the risk.

For postulated occurrences with high risk values, the Team identified strategies to handle the risk of a postulated occurrence that would reduce the probability and/or the consequence of the occurrence. The new values for probability and/or consequences were established along with the explanation of the risk handling strategy. The Team determined the impact of the identified strategies on the risk value due to implementation of these strategies. The final risk values were used as input to the downselection process for determination of the Short List of alternatives.

Additional information on the preliminary risk assessment process can be found in Reference 16. 


\section{$9.2 \quad$ Risk Assessment Results}

The results of the risk assessment process following risk handling are provided in Table 1 .

Table 1: Risk Assessment Overview

\begin{tabular}{|c|c|c|c|c|}
\hline Alternative & $\begin{array}{l}\text { High Risk } \\
\text { (No.) }\end{array}$ & $\begin{array}{l}\text { Moderate Risk } \\
\text { (No.) }\end{array}$ & $\begin{array}{l}\text { Low Risk } \\
\text { (No.) }\end{array}$ & $\begin{array}{c}\text { Number of Risks } \\
\text { Identified } \\
\text { for Alternative }\end{array}$ \\
\hline $\begin{array}{l}\text { Fractional Crystallization - DWPF } \\
\text { Vitrification }\end{array}$ & 2 & 4 & 8 & 14 \\
\hline $\begin{array}{l}\text { Electrochemical Separation and Destruction } \\
\text { - DWPF Vitrification }\end{array}$ & 10 & 5 & 6 & 21 \\
\hline Elutable Ion Exchange - DWPF Vitrification & 0 & 12 & 8 & 20 \\
\hline $\begin{array}{l}\text { Potassium Removal followed by TPB } \\
\text { Precipitation }\end{array}$ & 3 & 14 & 10 & 27 \\
\hline $\begin{array}{l}\text { Acid Side Ion Exchange - DWPF } \\
\text { Vitrification }\end{array}$ & 1 & 18 & 10 & 29 \\
\hline $\begin{array}{l}\text { Crystalline Silicotitanate (CST) Ion } \\
\text { Exchange - DWPF Vitrification }\end{array}$ & 0 & 15 & 6 & 21 \\
\hline $\begin{array}{l}\text { Crystalline Silicotitanate (CST) Ion } \\
\text { Exchange - New Facility Vitrification }\end{array}$ & 0 & 12 & 8 & 20 \\
\hline Zeolite Ion Exchange - DWPF Vitrification & 2 & 15 & 8 & 25 \\
\hline $\begin{array}{l}\text { Crystalline Silicotitanate (CST) Ion } \\
\text { Exchange - Ceramic Waste Form }\end{array}$ & 1 & 12 & 8 & 21 \\
\hline Reduced Temperature ITP & 6 & 13 & 9 & 28 \\
\hline Catalyst Removal ITP & 4 & 10 & 4 & 18 \\
\hline ITP with Enhanced Safety Features & 6 & 18 & 2 & 26 \\
\hline Small Tank TPB & 1 & 4 & 8 & 13 \\
\hline $\begin{array}{l}\text { Caustic Side Solvent Extraction - DWPF } \\
\text { Vitrification }\end{array}$ & 3 & 20 & 6 & 29 \\
\hline $\begin{array}{l}\text { Acid Side Solvent Extraction - DWPF } \\
\text { Vitrification }\end{array}$ & 3 & 23 & 10 & 36 \\
\hline Direct Vitrification & 8 & 11 & 8 & 27 \\
\hline Supernate Separation - DWPF Vitrification & 5 & 18 & 5 & 28 \\
\hline Direct Disposal as Grout & 2 & 11 & 4 & 17 \\
\hline \multicolumn{4}{|c|}{ Total Number of Risks Identified } & 420 \\
\hline
\end{tabular}




\section{$\underline{10.0 \quad \text { Field Confirmation Visits }}$}

In order to validate the risks and information identified for the candidate alternatives, field confirmation trips were completed for sites representing the technologies identified in the candidate alternatives.

\section{$\underline{10.1 \quad \text { Locations/Sites }}$}

Table 2 identifies the sites visited and the technologies reviewed during the visits.

Table 2: Field Confirmation Trips

\begin{tabular}{|l|l|}
\hline \multicolumn{1}{|c|}{ Site Visited } & \multicolumn{1}{c|}{ Technology Reviewed } \\
\hline \multirow{4}{*}{ British Nuclear Fuels plc (BNFL) - Sellafield } & Non-elutable Ion Exchange \\
\cline { 2 - 2 } & Solvent Extraction \\
\cline { 2 - 2 } & Vitrification \\
\cline { 2 - 2 } & Grout Encapsulation \\
\cline { 2 - 2 } Hanford & Precipitation and Filtration \\
\cline { 2 - 2 } & Fractional Crystallization \\
\cline { 2 - 2 } & Non-elutable Ion Exchange \\
\cline { 2 - 2 } & Elutable Ion Exchange \\
\cline { 2 - 2 } & Precipitation \\
\cline { 2 - 2 } West Valley Nuclear Services (WVNS) & Solid - Liquid Separation \\
\cline { 2 - 2 } & Zeolite Ion Exchange \\
\cline { 2 - 2 } & Waste Vitrification \\
\hline Oak Ridge National Laboratory (ORNL) & CST Ion Exchange \\
\cline { 2 - 2 } & Elutable Ion Exchange \\
\hline Idaho National Engineering and Environmental & Acid Side Solvent Extraction \\
\cline { 2 - 2 } Laboratory (INEEL) & Acid Side Ion Exchange \\
\hline
\end{tabular}

\subsection{Summary of Observations}

The site visits broadly confirmed the assessment process applied and the preliminary risks identified by the Team. The discussions and plant tours provided information that was used in subsequent evaluation of the Initial List alternatives. 


\section{Hanford}

The Hanford Site was visited May 7 and 8, 1998 (Reference 17). Key information obtained at Hanford is summarized below:

- PNNL has shown crystalline silicotitanate (CST) can be made into a ceramic waste form having excellent leachability characteristics.

- Numatec Hanford Company (NHC) personnel made a "clean salt" (unrestricted release from the laboratory with an activity of $4 \mathrm{pCi} / \mathrm{gr}$ ) from Hanford wastes using multiple fractional crystallization cycles. A decontamination factor (df) of 50-100 is realized with a single crystallization cycle.

- NHC personnel stated the French have developed and cold tested an ion exchange "sliding column". Airlifts are used, therefore no moving parts are needed.

- Hanford was able to dispose of Duolite ARC-359 spent resin as "low level mixed waste". This was accomplished by elution using normal flow through the column, soaking the eluted resin in fresh eluent in a tank for a week, and then using isotopic displacement (Cs for Cs-137) for one day.

- The Hanford consensus: Ion exchange is preferred over solvent extraction. CST and resorcinol formaldehyde (RF) are resins of choice.

\section{West Valley Nuclear Services (WVNS)}

The West Valley Demonstration Project Site was visited on May 19, 1998 (Reference 18). The topical areas of supernate treatment using Zeolite Ion Exchange (Operators and Engineering Perspective) and Waste Vitrification were reviewed and discussed. Key information obtained at West Valley is summarized below:

- In order to transfer and blend the Zeolite consistently in preparation for vitrification, WVNS had to install an in-line grinder to reduce particle size from 800 micron to 50 micron.

- To date, WVNS has not observed or been negatively effected by any secondary catalytic reaction caused by the Zeolite.

- WVNS was required to make significant operational and material handling modifications to account for the heat of hydration of the Zeolite during resin preparation and column changing.

- Zeolite fines management and handling during column changing has been a major challenge with issues similar to the frit transfer and handling problems experienced at the DWPF.

- WVNS originally utilized the CS-100 ion exchange resin but has retired the material because of significant supplier procurement problems/issues.

- The removal of entrained sludge from the supernate stream by cross flow filtration has been very successful. 600,000 gallons have been filtered with only two back pulse cleanings. 


\section{Idaho National Engineering and Environmental Laboratory}

The INEEL was visited on May 5, 1998 (Reference 19). Key information obtained at the INEEL is summarized below:

- The leading candidate for acid side solvent extraction at INEEL is cobalt dicarbollide in nitrobenzene. A very polar solvent is needed, hence the use of nitrobenzene. Fluorinated ethers are being investigated as alternatives but they are combustible and release fluoride. Tests at INEEL have achieved 98.3\% Cs removal. In 1996, Russia ran this process at Mayak on an industrial scale and removed cesium from 320,000 liters of High Level Waste. They used a chlorinated cobalt dicarbollide, which appears to have good radiation stability. Substituted dicarbollide products have been reported under high radiation exposure. INEEL has two small $(2-2.5 \mathrm{~cm})$ centrifugal contactor banks for cold studies (ORNL and Russian designs) and one small centrifugal bank in their shielded cells for tracer and HLW studies. INEEL is also looking at solvent extraction to remove transuranic (TRU) material and $\mathrm{Sr}$ from their waste.

- INEEL's backup cesium extractant is calixarene crown ether. This material is susceptible to nitration in strong acid. Radiation studies have shown that after one to two year equivalent exposure there is only a $20 \%$ reduction in extraction efficiency. The flammability of the solvent is similar to the PUREX solvent.

- The leading acid side ion exchange candidate for INEEL is ammonium molybdophosphate (AMP) on Polyacrylonitrile (PAN). It has excellent kinetics (26-100 column volumes/hr, compared to CST's 6 column volumes/hr) and a capacity four to five times better than CST in acid. This resin can be eluted with a strong $\mathrm{NH}_{4}{ }^{+}$solution (reversible) or reacted with $0.1-1 \mathrm{M} \mathrm{NaOH}$ (irreversible). The Czechs loaded a 6-inch column with radioactive Cesium and required only ambient cooling.

- INEEL has successfully used cross-flow filtration for solids removal in their feed prior to separation. Their feed contains approximately $2 \%$ solids. This was tested in their hot cells with actual waste.

- INEEL is set up for cold and hot testing of acid side solvent extraction and acid side ion exchange. They indicated a willingness to test SRS waste on their systems. They would need one to two liters of waste for the testing and SRS would need to resolve sample and waste shipping issues. INEEL could more easily test SRS simulants with radioactive tracers. 


\section{$\underline{\text { Oak Ridge National Laboratory }}$}

Oak Ridge National Laboratory (ORNL) was visited on May 21, 1998 (Reference 20). Key information obtained at ORNL is summarized below:

- ORNL has eight tanks each with a capacity of 50,000 gallons located in Melton Valley. These tanks contain the waste from historical pilot operations. Six new 100,000-gallon tanks are being built.

- The ORNL waste is not High Level Waste, but is remote handled transuranic waste. In comparison to SRS waste, it has more calcium and carbonate and is cooled for a longer period of time.

- ORNL has performed an evaluation of a range of ion exchange resins for separation of cesium from the waste, including CST, CS-100, potassium cobalt hexacyanoferrate, resorcinol formaldehyde, Super Lig 644C and a 3M Empore material with Super Lig 644C bound into it. On the basis of the tests, CST was selected for a hot demonstration.

- The demonstration has been completed with the processing of 31,000 gallons containing $1200 \mathrm{Ci}$ of cesium.

- Full production is scheduled to begin in the near future.

- The CST is loaded with Cs to only $40 \%$ of its limit (at the feed concentration) in order to keep it within Class $\mathrm{C}$ waste limits. It is intended to encapsulate it in cement in High Integrity Containers (HICs) and transfer it to Nevada Test Site (NTS) for disposal.

\section{Sellafield}

BNFL Sellafield plant was visited from May 4, 1998 through May 11, 1998 (Reference 21). Key information obtained at Sellafield is summarized below:

The primary technologies evaluated were:

- Solvent extraction (THORP - Thermal Oxide Reprocessing Plant)

- Glass solidification (WVP - Windscale Vitrification Plant)

- Precipitation and filtration (EARP - Enhanced Actinide Removal Plant)

- Grout encapsulation (WEP - Waste Encapsulation Plant and WPEP - Waste Packaging and Encapsulation Plant)

- Ion exchange (SIXEP - Site Ion Exchange Plant)

- Engineering process (TWRS - Tank Waste Remediation System/Hanford) 


\section{$\underline{\text { General }}$}

- The team reviews concentrated on identification of operational/technical issues, testing issues for first of a kind facilities, safety culture, authorization basis and management approach to risk handling, and production throughput versus design.

- BNFL's research and development program on encapsulation of "Intermediate" and Low Level Waste has led to the selection of grouting (cement encapsulation) for virtually all solid and slurry type wastes.

$\underline{\text { Technology Specific }}$

- The principal risks observed/identified were:

- Post precipitation in THORP illustrates that, however thorough the development work, scale up to full scale production is never risk free.

- There were unexpected gas releases from a pulsed column.

- Nitric acid leaks/spillages are a fact of life.

- Vitrification of high sodium streams is unproven in a radioactive environment.

- BNFL is a leader in the application of grout technology to waste stabilization

- BNFL grouts waste streams with activity levels similar to SRS salt.

- Zeolite ion exchange as a polishing step is a simple reliable operation.

- $\mathrm{pH}$ control in the steep part of the $\mathrm{pH}$ curve requires careful development and testing but is achievable.

- Solvent extraction is a mature but relatively complex technology.

- BNFL's HLW glass canisters are extremely radioactive and their "consumable" melter design is very different from the approach taken in DWPF.

- Ceramic waste forms were being studied for possible future application, but the assumption was that high temperatures and pressures would be required for their manufacture. 


\subsection{Flow Sheet Analysis}

To evaluate the technical aspects of the Initial List alternatives, a flowsheet for each alternative was completed and used to ensure alternatives are compared in a consistent technical manner.

The flowsheets were developed utilizing a structured method of analysis and assessment. They provide information on a specific process system and integration of that system with existing interfaces. The information consists of a process flow diagram (PFD) that depicts the various flow paths of the system along with tabular data (such as flow rates, cycle time, etc.) identified for each flow stream.

\subsection{Basis, Constraints, Assumptions}

In order to provide the flowsheets for the Initial List alternatives during Phase II, specific and global constraints and assumptions were defined and documented for each alternative. These assumptions were based on the technical information/data available for the various processes as well as the expertise of the Flowsheet Task Team.

This information can be found in WSRC-RP-98-00166, "Bases, Assumptions, and Results of the Flowsheet Calculations for the Initial Eighteen Salt Disposition Alternatives" (Reference 12).

\subsection{Flow Sheet Approach}

Due to the complexity of the alternatives and details required, the Flowsheet Task Team developed mathematical models and PFDs as described in Reference 23 to provide a level of analysis that supported the Phase II evaluation process. The engineering calculations and models were developed from consistent bases, assumptions, and constraints with as many common unit operations as possible.

During Phase II, the calculated variables were limited to mass balances such as cycle times, mass and volumetric flow rates entering and exiting each alternative, emission levels, waste work off schedules, and final waste form production rates. This defined approach to modeling met the requirements documented for Phase II and ensured the models developed could be used as a starting point for Phase III flowsheet efforts.

The information generated during the flowsheet analysis was handled as outlined in HLWSDT-980010, "Position Paper on the Approach to Information Handling, Analysis and Reporting" (Reference 22). 


\subsection{Flow Sheet Results}

All Initial List alternatives were successfully flowsheeted to the needs for the Phase II evaluation. The flowsheet modeling results are summarized on the Process Flow Diagram(s) for the Initial List alternatives. The details of the flowsheet results runs can be found in Reference 12 .

A summary of the results for all of the options is presented in Tables 3 through 6 . The tables specify the raw materials consumed, the waste streams processed, the products of the various options, and environmental releases. The base case represents the current ITP facility operation if processing could resume under the current set of constraints outlined for ITP operation.

These tables represent $100 \%$ attainment. It will require 20 years of elapsed time to operate 15 years due to melter replacements. The maximum utility is $75 \%$. To convert the quantities in Tables 3 through 6 to life cycle values, a factor of 11.25 ( $15 \times 0.75)$ should be applied to all options except option 17. Option 17 requires a significant DWPF life extension (160 years). Therefore, items related to DWPF (option 17 only) should have a factor of 160 applied for life cycle quantities. Each canister has a volume of 180 liters which can hold approximately $3800 \mathrm{lbs}$. to $4000 \mathrm{lbs}$. of glass.

The models and material balances are based on the assumptions and bases presented in Reference 12. The complete material balance and flow sheet diagrams are included in Appendix A of Reference 12 
Table 3: Raw Materials Consumed

\begin{tabular}{|c|c|c|c|c|c|c|c|c|c|c|c|}
\hline Option \# & Option Title & $\begin{array}{l}\text { NaTPB } \\
\mathrm{kgal} / \mathrm{yr}\end{array}$ & $\begin{array}{c}\mathrm{ST} \\
\mathrm{klb} / \mathrm{yr}\end{array}$ & $\begin{array}{l}\text { IX Resin } \\
\text { klb/yr }\end{array}$ & $\begin{array}{l}\mathrm{NaOH} \\
\mathrm{kgal} / \mathrm{yr} \\
50 \mathrm{wt} \%\end{array}$ & $\begin{array}{c}\text { HNO3 } \\
\text { klb/yr } \\
50 \text { wt } \%\end{array}$ & $\begin{array}{l}\text { Solvent } \\
\mathrm{kgal} / \mathrm{yr}\end{array}$ & $\begin{array}{l}\text { NaNO2 } \\
\text { klb/yr }\end{array}$ & $\begin{array}{l}\text { Process } \\
\mathrm{H} 2 \mathrm{O} \\
\mathrm{kgal} / \mathrm{yr}\end{array}$ & $\begin{array}{l}\text { Glass } \\
\text { Formers } \\
\text { klb/yr }\end{array}$ & $\begin{array}{c}\text { Ceramic } \\
\text { Formers } \\
\text { klb/yr }\end{array}$ \\
\hline & Base Case & 174.8 & 4 & -- & 27.9 & 36.9 & -- & 61.2 & 722 & 303.3 & -- \\
\hline 1 & $\begin{array}{l}\text { Fractional Crystallization - } \\
\text { DWPF Vit. }\end{array}$ & -- & 8.2 & -- & 452 & 3347 & -- & 88 & -- & 1370 & -- \\
\hline 2 & $\begin{array}{l}\text { Electrochemical Separation } \\
\text { and Destruction - DWPF } \\
\text { Vit. }\end{array}$ & -- & -- & -- & 40.6 & 100 & -- & 88.9 & 4322 & 1625 & -- \\
\hline 3 & $\begin{array}{l}\text { Elutable Ion Exchange - } \\
\text { DWPF Vit. }\end{array}$ & -- & 8.2 & 25.9 & 73.6 & 413 & -- & 121 & 602 & 1103 & -- \\
\hline 4 & $\begin{array}{l}\text { Potassium Removal } \\
\text { Followed } \\
\text { by TPB Precipitation }\end{array}$ & 9.9 & 8.2 & 2 & 411 & 2088 & -- & 117 & 4763 & 968 & -- \\
\hline 5 & $\begin{array}{l}\text { Acid Side Ion Exchange - } \\
\text { DWPF Vit. }\end{array}$ & -- & 8.2 & 37.2 & 1117 & 39280 & -- & 103 & 354 & 1170 & -- \\
\hline 6 & $\begin{array}{l}\text { CST Ion Exchange to } \\
\text { DWPF - } \\
\text { DWPF Vit. }\end{array}$ & -- & -- & 70.9 & 45.4 & 137 & -- & 241 & 341 & 1216 & -- \\
\hline 7 & $\begin{array}{l}\text { CST Ion Exchange - } \\
\text { New Facility Vit. }\end{array}$ & -- & -- & 70.9 & 26.7 & -- & -- & -- & 341 & 372 & -- \\
\hline 8 & $\begin{array}{l}\text { Zeolite Ion Exchange - } \\
\text { DWPF Vit. }\end{array}$ & -- & 8.2 & 620 & 558 & 125 & -- & 107 & 3523 & 1630 & -- \\
\hline 9 & $\begin{array}{l}\text { CST Ion Exchange - } \\
\text { Ceramic } \\
\text { Waste Form }\end{array}$ & -- & -- & 70.9 & 26.7 & -- & -- & -- & 341 & -- & 82.3 \\
\hline 10 & Reduced Temperature ITP & 179 & 2 & -- & 40 & 83.6 & -- & 87.6 & 1478 & 563.4 & -- \\
\hline 11 & Catalyst Removal ITP & 211 & 8.2 & -- & 40 & 83.6 & -- & 87.6 & 1874 & 563.4 & -- \\
\hline 12 & $\begin{array}{l}\text { ITP with Enhanced Safety } \\
\text { Features }\end{array}$ & 179 & 2.0 & -- & 40 & 83.6 & -- & 87.6 & 1443 & 563.4 & -- \\
\hline
\end{tabular}


Table 3: Raw Materials Consumed (con't)

\begin{tabular}{|c|c|c|c|c|c|c|c|c|c|c|c|}
\hline Option \# & Option Title & $\begin{array}{l}\text { NaTPB } \\
\mathrm{kgal} / \mathrm{yr}\end{array}$ & $\begin{array}{c}\text { ST } \\
\mathrm{klb} / \mathrm{yr}\end{array}$ & $\begin{array}{l}\text { IX Resin } \\
\text { klb/yr }\end{array}$ & $\begin{array}{c}\mathrm{NaOH} \\
\mathrm{kgal} / \mathrm{yr} \\
50 \mathrm{wt} \%\end{array}$ & $\begin{array}{c}\text { HNO3 } \\
\text { klb/yr } \\
50 \text { wt \% }\end{array}$ & $\begin{array}{l}\text { Solvent } \\
\mathrm{kgal} / \mathrm{yr}\end{array}$ & $\begin{array}{l}\text { NaNO2 } \\
\text { klb/yr }\end{array}$ & $\begin{array}{c}\text { Process } \\
\text { H2O } \\
\mathrm{kgal} / \mathrm{yr}\end{array}$ & $\begin{array}{c}\text { Glass } \\
\text { Formers } \\
\text { klb/yr }\end{array}$ & $\begin{array}{c}\text { Ceramic } \\
\text { Formers } \\
\text { klb/yr }\end{array}$ \\
\hline 13 & Small Tank TPB & 263 & 5 & -- & 42 & 110 & -- & 104 & 5099 & 868.6 & -- \\
\hline 14 & $\begin{array}{l}\text { Caustic Side Solvent } \\
\text { Extraction }\end{array}$ & -- & -- & -- & 53.4 & 132 & 1 & 117 & 103 & 966 & -- \\
\hline 15 & $\begin{array}{l}\text { Acid Side Solvent } \\
\text { Extraction }\end{array}$ & -- & 8.2 & -- & 651.6 & 45482 & 1 & -- & 102 & 960 & -- \\
\hline 16 & Direct Vitrification & -- & 8.2 & -- & -- & -- & -- & -- & -- & 33755 & -- \\
\hline 17 & $\begin{array}{l}\text { Supernate Separation - } \\
\text { DWPF Vit. }\end{array}$ & -- & 8.2 & -- & 43.2 & 16.3 & -- & 94.8 & 5964 & 860 & -- \\
\hline 18 & Direct Disposal as Grout & -- & 8.2 & -- & -- & -- & -- & -- & -- & -- & -- \\
\hline
\end{tabular}

Table 4: Waste Processed

\begin{tabular}{|c|l|c|c|}
\hline Option \# & Option Title & $\begin{array}{c}\text { Salt Solution } \\
\mathbf{k g a l} / \mathbf{y r}\end{array}$ & $\begin{array}{c}\text { Sludge } \\
\mathbf{k g a l} / \mathbf{y r}\end{array}$ \\
\hline $\mathbf{1}$ & Base Case & 3420 & 97.3 \\
\hline $\mathbf{2}$ & $\begin{array}{l}\text { Fractional Crystallization - } \\
\text { DWPF Vit. }\end{array}$ & $\begin{array}{l}\text { Electrochemical Separation } \\
\text { and Destruction - DWPF Vit. }\end{array}$ & 6938 \\
\hline $\mathbf{3}$ & $\begin{array}{l}\text { Elutable lon Exchange - } \\
\text { DWPF Vit. }\end{array}$ & 1156 & 297 \\
\hline $\mathbf{4}$ & $\begin{array}{l}\text { Potassium Removal Followed } \\
\text { by TPB Precipitation }\end{array}$ & 6938 & 430 \\
\hline $\mathbf{5}$ & $\begin{array}{l}\text { Acid Side lon Exchange - } \\
\text { DWPF Vit. }\end{array}$ & 6938 & 415 \\
\hline $\mathbf{6}$ & $\begin{array}{l}\text { CST lon Exchange to DWPF - } \\
\text { DWPF Vit. }\end{array}$ & 6938 & 430 \\
\hline
\end{tabular}


Table 4: Waste Processed (con't)

\begin{tabular}{|c|c|c|c|}
\hline Option \# & Option Title & $\begin{array}{c}\text { Salt Solution } \\
\mathrm{kgal} / \mathrm{yr}\end{array}$ & $\begin{array}{l}\text { Sludge } \\
\mathrm{kgal} / \mathrm{yr}\end{array}$ \\
\hline 7 & $\begin{array}{l}\text { CST Ion Exchange - } \\
\text { New Facility Vit. }\end{array}$ & 6938 & -- \\
\hline 8 & $\begin{array}{l}\text { Zeolite lon Exchange - } \\
\text { DWPF Vit. } \\
\end{array}$ & 5064 & 352 \\
\hline 9 & $\begin{array}{l}\text { CST lon Exchange - Ceramic } \\
\text { Waste Form }\end{array}$ & 6938 & -- \\
\hline 10 & Reduced Temperature ITP & 4442 & 209.5 \\
\hline 11 & Catalyst Removal ITP & 4761 & 209.5 \\
\hline 12 & $\begin{array}{l}\text { ITP with Enhanced Safety } \\
\text { Features }\end{array}$ & 4509 & 209.5 \\
\hline 13 & Small Tank TPB Precipitation & 6938 & 292 \\
\hline 14 & $\begin{array}{l}\text { Caustic Side Solvent } \\
\text { Extraction }\end{array}$ & 7765 & 430 \\
\hline 15 & $\begin{array}{l}\text { Acid Side Solvent } \\
\text { Extraction }\end{array}$ & 7680 & 430 \\
\hline 16 & Direct Vitrification & 6938 & -- \\
\hline 17 & Supernate Separation - & 7204 Diss. Salt & -- \\
\hline & DWPF Vit. & 105 Conc. Sup. & 469 \\
\hline 18 & Direct Disposal as Grout & 6938 & -- \\
\hline
\end{tabular}


Table 5: Products

\begin{tabular}{|c|c|c|c|c|c|c|}
\hline Option \# & Option Title & $\begin{array}{l}\text { Saltstone } \\
\text { kgal/yr }\end{array}$ & $\begin{array}{l}\text { DWPF } \\
\text { Glass } \\
\text { klb/yr }\end{array}$ & $\begin{array}{c}\text { New Facility } \\
\text { Glass } \\
\text { klb/yr }\end{array}$ & $\begin{array}{c}\text { Ceramic } \\
\text { Waste Form } \\
\text { klb/yr }\end{array}$ & $\begin{array}{c}\text { Tank Farm } \\
\text { Recycle } \\
\text { kgal/yr }\end{array}$ \\
\hline & Base Case & 6402 & 565 & -- & -- & 1233 \\
\hline 1 & $\begin{array}{l}\text { Fractional Crystallization } \\
\text { DWPF Vit. }\end{array}$ & 15922 & 2190 & -- & -- & 1353 \\
\hline 2 & $\begin{array}{l}\text { Electrochemical Separation } \\
\text { and Destruction - DWPF Vit. }\end{array}$ & 7740 & 2635 & -- & -- & 1366 \\
\hline 3 & $\begin{array}{l}\text { Elutable lon Exchange - } \\
\text { DWPF Vit. }\end{array}$ & 11130 & 1589 & -- & -- & 1884 \\
\hline 4 & K+ Removal/TPB Precipitation & 13690 & 1388 & $\overline{--}$ & -- & 1797 \\
\hline 5 & $\begin{array}{l}\text { Acid Side lon Exchange - } \\
\text { DWPF Vit. }\end{array}$ & 17980 & 1646 & -- & -- & 1587 \\
\hline 6 & $\begin{array}{l}\text { CST Ion Exchange to DWPF - } \\
\text { DWPF Vit. }\end{array}$ & 11080 & 1643 & -- & -- & 1431 \\
\hline 7 & $\begin{array}{l}\text { CST Ion Exchange - } \\
\text { New Facility Vit. }\end{array}$ & 11080 & * & 443 & -- & $141^{\star * *}$ \\
\hline 8 & $\begin{array}{l}\text { Zeolite Ion Exchange - } \\
\text { DWPF Vit. }\end{array}$ & 16872 & 2371 & -- & -- & 1644 \\
\hline 9 & $\begin{array}{l}\text { CST Ion Exchange - Ceramic } \\
\text { Waste Form }\end{array}$ & 11080 & * & -- & 253 & $131^{\star *}$ \\
\hline 10 & Reduced Temperature ITP & 8969 & 1053 & -- & -- & 1770 \\
\hline 11 & Catalyst Removal ITP & 8047 & 1053 & -- & -- & 1770 \\
\hline 12 & $\begin{array}{l}\text { ITP with Enhanced Safety } \\
\text { Features }\end{array}$ & 8715 & 1053 & -- & -- & 1770 \\
\hline 13 & Small Tank TPB Precipitation & 16727 & 1701 & -- & -- & 2380 \\
\hline 14 & $\begin{array}{l}\text { Caustic Side Solvent } \\
\text { Extraction }\end{array}$ & 12061 & 1388 & -- & -- & 1797 \\
\hline
\end{tabular}


Table 5: Products (con't)

\begin{tabular}{|c|l|c|c|c|c|c|}
\hline Option \# & Option Title & $\begin{array}{c}\text { Saltstone } \\
\mathbf{k g a l} / \mathbf{y r}\end{array}$ & $\begin{array}{c}\text { DWPF } \\
\text { Glass } \\
\mathbf{k l b} / \mathbf{y r}\end{array}$ & $\begin{array}{c}\text { New Facility } \\
\text { Glass } \\
\mathbf{k l b} / \mathbf{y r}\end{array}$ & $\begin{array}{c}\text { Ceramic } \\
\text { Waste Form } \\
\mathbf{k l b} / \mathbf{y r}\end{array}$ & $\begin{array}{c}\text { Tank Farm } \\
\mathbf{R e c y c l e} \\
\mathbf{k g a l} / \mathbf{y r}\end{array}$ \\
\hline $\mathbf{1 5}$ & $\begin{array}{l}\text { Acid Side Solvent } \\
\text { Extraction }\end{array}$ & 20190 & 1371 & -- & -- & 1703 \\
\hline $\mathbf{1 6}$ & Direct Vitrification & -- & -- & 41905 & -- & 6695 \\
\hline $\mathbf{1 7}$ & $\begin{array}{l}\text { Supernate Separation - } \\
\text { DWPF Vit. }\end{array}$ & 7120 & 1360 & -- & & -- \\
\hline $\mathbf{1 8}$ & Direct Disposal as Grout & 11504 & -- & -- & -- & 1453 \\
\hline
\end{tabular}

* Same as sludge only.

** DWPF recycle from sludge only operation should be added to this value.

Table 6: Environmental Releases

\begin{tabular}{|c|c|c|c|c|c|c|}
\hline Option \# & Option Title & \begin{tabular}{|cc} 
Air & $\begin{array}{c}\text { NOX } \\
\text { tons/yr }\end{array}$ \\
\end{tabular} & $\begin{array}{c}\text { Benzene } \\
\text { tons/yr }\end{array}$ & $\begin{array}{c}\begin{array}{c}\text { Liquid } \\
\text { Benzene } \\
\mathrm{kgal} / \mathrm{yr}\end{array} \\
\end{array}$ & $\begin{array}{c}\text { Solvents } \\
\text { kgal/yr }\end{array}$ & $\begin{aligned} \text { Solid } & \\
& \text { Resin } \\
& \text { klb/yr }\end{aligned}$ \\
\hline & Base Case & 10.2 & 102 & 10.6 & -- & -- \\
\hline 1 & $\begin{array}{l}\text { Fractional Crystallization - } \\
\text { DWPF Vit. }\end{array}$ & 99 & -- & -- & -- & -- \\
\hline 2 & $\begin{array}{l}\text { Electrochemical Separation } \\
\text { and Destruction - DWPF Vit. }\end{array}$ & $\begin{array}{c}(\mathrm{NH} 3) \\
711 \\
\end{array}$ & -- & -- & -- & -- \\
\hline 3 & $\begin{array}{l}\text { Elutable lon Exchange - } \\
\text { DWPF Vit. }\end{array}$ & 70.1 & -- & -- & -- & 25.9 \\
\hline 4 & $\begin{array}{l}\text { Potassium Removal Followed } \\
\text { by TPB Precipitation }\end{array}$ & 26 & 329 & 1.6 & -- & 2 \\
\hline 5 & $\begin{array}{l}\text { Acid Side lon Exchange - } \\
\text { DWPF Vit. }\end{array}$ & 545 & -- & -- & -- & 5.6 \\
\hline 6 & $\begin{array}{l}\text { CST lon Exchange to DWPF - } \\
\text { DWPF Vit. }\end{array}$ & 26.6 & -- & -- & -- & -- \\
\hline
\end{tabular}


Table 6: Environmental Releases (con't)

\begin{tabular}{|c|c|c|c|c|c|c|}
\hline Option \# & Option Title & Air $\begin{array}{c}\text { NOX } \\
\text { tons/yr }\end{array}$ & $\begin{array}{l}\text { Benzene } \\
\text { tons/yr }\end{array}$ & $\begin{array}{c}\text { Liquid } \\
\begin{array}{c}\text { Benzene } \\
\mathrm{kgal} / \mathrm{yr}\end{array}\end{array}$ & $\begin{array}{l}\text { Solvents } \\
\mathrm{kgal} / \mathrm{yr}\end{array}$ & $\begin{array}{r}\text { Solid } \\
\begin{array}{r}\text { Resin } \\
\text { klb/yr }\end{array}\end{array}$ \\
\hline 7 & $\begin{array}{l}\text { CST Ion Exchange -New } \\
\text { Facility Vit. }\end{array}$ & -- & -- & -- & -- & -- \\
\hline 8 & $\begin{array}{l}\text { Zeolite Ion Exchange - } \\
\text { DWPF Vit. }\end{array}$ & 22.3 & -- & -- & -- & -- \\
\hline 9 & $\begin{array}{l}\text { CST Ion Exchange - Ceramic } \\
\text { Waste Form }\end{array}$ & -- & -- & -- & -- & -- \\
\hline 10 & Reduced Temperature ITP & 23.6 & 10.2 & 28.7 & -- & -- \\
\hline 11 & Catalyst Removal ITP & 23.6 & 10.2 & 28.7 & -- & -- \\
\hline 12 & $\begin{array}{l}\text { ITP with Enhanced Safety } \\
\text { Features }\end{array}$ & 23.6 & 658 & 28.7 & -- & -- \\
\hline 13 & Small Tank TPB Precipitation & 33.4 & 2.6 & 31.6 & -- & -- \\
\hline 14 & $\begin{array}{l}\text { Caustic Side Solvent } \\
\text { Extraction }\end{array}$ & 27 & -- & -- & 1 & -- \\
\hline 15 & $\begin{array}{l}\text { Acid Side Solvent } \\
\text { Extraction }\end{array}$ & 1338 & -- & -- & 1 & -- \\
\hline 16 & Direct Vitrification & 5640 & -- & -- & -- & $\overline{--}$ \\
\hline 17 & $\begin{array}{l}\text { Supernate Separation - } \\
\text { DWPF Vit. }\end{array}$ & 46.8 & -- & -- & -- & -- \\
\hline 18 & Direct Disposal as Grout & -- & -- & -- & -- & -- \\
\hline
\end{tabular}




\subsection{Preliminary Life Cycle Cost Comparison}

Life Cycle Cost (LCC) was conservatively estimated in Phase II to provide additional decision information for the alternative evaluation process as shown in Table 7. The estimate permitted the comparison of the alternatives on an equivalent cost basis. Preconceptual grade estimates will be available for the Short List alternatives following preconceptual engineering scope definition in Phase III.

Although Federal Repository costs for the final waste form are normally included in LCC estimates, the Repository costs were estimated separately for this comparison. Uncertainties in packaging, transportation, and final Federal Repository configuration could have resulted in Repository cost overwhelming the Operating and Project cost of the candidate alternative.

Phase II estimating techniques included scaling from existing facilities such as DWPF, use of prior estimates (from DWPF studies and Hanford) for ion exchange facilities and expert opinion. Major operating cost variants such as the amount of grout to be produced at the Saltstone Facility and the number of glass canisters at DWPF from the baseline amount were also considered. Engineering definition was limited to flowsheet parameters developed during Phase II selection process.

The following ranges were used for the preliminary LCC estimates developed during the preconceptual stage for the Initial List of alternatives:

- Less than $\$ 2$ billion

- $\$ 2$ billion to $\$ 4$ billion

- $\$ 4$ billion to $\$ 8$ billion

- $\$ 8$ billion to $\$ 16$ billion

- In Excess of $\$ 16$ billion

Additional information on the Life Cycle Cost determination can be found in HLW-SDT-980013, "Position Paper on Preliminary Life Cycle Cost Analysis to Select the Short List of Alternatives" (Reference 24).

The bases for the preliminary life cycle cost estimates as well as the spreadsheets for each alternative are provided in HLW-SDT-980018, "Results Report on Preliminary Life Cycle Cost Estimates for Initial List Alternatives" (Reference 11). 
Table 7 provides a comparison between the Preliminary LCC of the eighteen alternatives.

Table 7: Preliminary Life Cycle Cost Comparison

\begin{tabular}{|c|c|c|c|c|c|}
\hline Alternative & $\begin{array}{l}\text { Less than } \\
\$ 2 \text { billion }\end{array}$ & $\begin{array}{c}\$ 2 \text { billion } \\
\text { to } \\
\$ 4 \text { billion }\end{array}$ & $\begin{array}{c}\$ 4 \text { billion } \\
\text { to } \\
\$ 8 \text { billion }\end{array}$ & $\begin{array}{c}\$ 8 \text { billion } \\
\text { to } \\
\$ 16 \text { billion }\end{array}$ & $\begin{array}{c}\text { In } \\
\text { Excess of } \\
\$ 16 \\
\text { billion }\end{array}$ \\
\hline $\begin{array}{l}\text { Fractional Crystallization - DWPF } \\
\text { Vitrification }\end{array}$ & & & $\mathrm{X}$ & & \\
\hline $\begin{array}{l}\text { Electrochemical Separation and Destruction } \\
\text { - DWPF Vitrification }\end{array}$ & & & & $\mathrm{X}$ & \\
\hline $\begin{array}{l}\text { Elutable Ion Exchange - DWPF } \\
\text { Vitrification }\end{array}$ & & $\mathrm{X}$ & & & \\
\hline $\begin{array}{l}\text { Potassium Removal followed by TPB } \\
\text { Precipitation }\end{array}$ & & $\mathrm{X}$ & & & \\
\hline $\begin{array}{l}\text { Acid-side Ion Exchange - DWPF } \\
\text { Vitrification }\end{array}$ & & $\mathrm{X}$ & & & \\
\hline $\begin{array}{l}\text { Crystalline Silicotitanate (CST) Ion } \\
\text { Exchange - DWPF Vitrification }\end{array}$ & & $\mathrm{X}$ & & & \\
\hline $\begin{array}{l}\text { Crystalline Silicotitanate (CST) Ion - New } \\
\text { Facility Vitrification }\end{array}$ & & & $\mathrm{X}$ & & \\
\hline Zeolite Ion Exchange - DWPF Vitrification & & & $\mathrm{X}$ & & \\
\hline $\begin{array}{l}\text { Crystalline Silicotitanate (CST) Ion } \\
\text { Exchange - Ceramic Waste Form }\end{array}$ & & $\mathrm{X}$ & & & \\
\hline Reduced Temperature ITP & $\mathrm{X}$ & & & & \\
\hline Catalyst Removal ITP & $\mathrm{X}$ & & & & \\
\hline ITP with Enhanced Safety Features & & $\mathrm{X}$ & & & \\
\hline Small Tank TPB & $\mathrm{X}$ & & & & \\
\hline $\begin{array}{l}\text { Caustic Side Solvent Extraction - DWPF } \\
\text { Vitrification }\end{array}$ & & $\mathrm{X}$ & & & \\
\hline $\begin{array}{l}\text { Acid Side Solvent Extraction - DWPF } \\
\text { Vitrification }\end{array}$ & & & $\mathrm{X}$ & & \\
\hline Direct Vitrification & & & & & $\mathrm{X}$ \\
\hline Supernate Separation - DWPF Vitrification & & & & $\mathrm{X}$ & \\
\hline
\end{tabular}




\begin{tabular}{|l|c|c|c|c|c|}
\hline Direct Disposal as Grout & $\mathrm{X}$ & & & & \\
\hline
\end{tabular}




\subsection{Alternative Evaluation Process}

The Team used input from multiple sources to perform the alternative evaluation to reach a Short List of alternatives. This input included the risk assessments, flowsheet analysis, trip reports, Life Cycle Costs and Team expertise. The process used to assign a weighted score to each alternative is discussed in subsequent sections.

\section{$\underline{13.1 \quad \text { Overview }}$}

The systematic process and methodology utilized by the Team to evaluate the Initial List of eighteen alternatives is formally known as Multi-Attribute Utility Analysis (MAUA). It is defined in the SEMP (Reference 5) and in more detail in HLW-SDT-980006, "Position Paper on the Definition and Utilization of Weighted Evaluation Criteria to Select the Short List of Alternatives" (Reference 25).

The Team evaluated each alternative against predetermined weighted evaluation criteria and associated utility functions. The outcome of this process is a weighted score of the Initial List of alternatives to assist in the down selection to a Short List.

\subsection{Selection Criteria}

The attributes deemed most important by the Team for comparison of the Initial List of alternatives are termed Evaluation Criteria.

Evaluation criteria identified in the Phase I Report were applied. Any additional evaluation criteria identified by the Team were required to have the following characteristics.

1. Independence from each other.

2. Address all necessary and sufficient functions and requirements for high-risk issues identified in preliminary risk assessments.

3. Universally understood by evaluators.

4. Differentiate meaningfully among alternatives without bias.

5. Be quantifiable (e.g., analysis, subject matter expertise, Team judgement, etc.)

A formal facilitated process was employed to select and define the evaluation criteria. Results of this process can be found in HLW-SDT-980012, "Results of the HLW Salt Disposition Systems Engineering Team Phase II Criteria Selection and Weighting for HLW Salt Disposition 'Initial List' Down Selection" (Reference 26).

The evaluation criteria selected and defined by the Team for the Phase II downselect from the Initial List to the Short List are summarized in Table 8. The primary criteria are referred to as Level 1 criteria and subcriteria are referred to as Level 2 criteria. 


\section{Table 8: Titles, Definitions, \& Weights of Evaluation Criteria Utilized in Phase II}

\begin{tabular}{|c|c|c|c|}
\hline Criterion Title & $\begin{array}{l}\text { Criterion } \\
\quad \#\end{array}$ & $\begin{array}{l}\text { Assigned } \\
\text { Weight }\end{array}$ & Definition \\
\hline Technology & 1.0 & 0.23 & $\begin{array}{l}\text { Maximize the confidence that underlying scientific } \\
\text { principles and engineering implementation will } \\
\text { result in adequate attainment. }\end{array}$ \\
\hline Scientific Maturity & 1.1 & 0.40 & $\begin{array}{l}\text { The level of scientific understanding needed to } \\
\text { minimize project risk. }\end{array}$ \\
\hline Engineering Maturity & 1.2 & 0.40 & $\begin{array}{l}\text { The level of applied engineering concepts needed to } \\
\text { minimize project risk. }\end{array}$ \\
\hline Process Simplicity & 1.3 & 0.20 & $\begin{array}{l}\text { Ease of Science implementation understanding by } \\
\text { operators }\end{array}$ \\
\hline Current Mission Interfaces & 2.0 & 0.15 & Impact on current SRS missions/programs \\
\hline DWPF & 2.1 & 0.25 & $\begin{array}{l}\text { Impact on DWPF (Table } 1 \text { Functions \& } \\
\text { Requirements). }\end{array}$ \\
\hline Saltstone & 2.2 & 0.15 & $\begin{array}{l}\text { Impact on Saltstone (Table } 1 \text { Functions \& } \\
\text { Requirements). }\end{array}$ \\
\hline Solid Waste & 2.3 & 0.10 & $\begin{array}{l}\text { Impact on Solid Waste (Table } 1 \text { Functions \& } \\
\text { Requirements). }\end{array}$ \\
\hline Tank Farm & 2.4 & 0.20 & $\begin{array}{l}\text { Impact on Tank Farm (Table } 1 \text { Functions \& } \\
\text { Requirements). }\end{array}$ \\
\hline $\begin{array}{r}\text { Tank Farm Space } \\
\text { Management }\end{array}$ & 2.5 & 0.30 & $\begin{array}{l}\text { Utilization of available Tank Farm storage and } \\
\text { resources as a function of time (HLW Salt } \\
\text { Disposition Interface Functional Performance } \\
\text { Requirement). }\end{array}$ \\
\hline Future Mission Interfaces & 3.0 & 0.07 & $\begin{array}{l}\text { Maximize the support of identified potential future } \\
\text { missions. }\end{array}$ \\
\hline $\begin{array}{l}\text { Regulatory/ISMS/ } \\
\text { Environmental }\end{array}$ & 4.0 & 0.23 & $\begin{array}{l}\text { Protect personnel and the environment from hazards } \\
\text { and releases of waste and pollution by ensuring } \\
\text { maximum application of intrinsic safety features. }\end{array}$ \\
\hline Public/Environment & 4.1 & 0.45 & $\begin{array}{l}\text { Protect the public and environment from hazards } \\
\text { and accidental releases of waste and pollution by } \\
\text { ensuring maximum application of intrinsic safety } \\
\text { features. }\end{array}$ \\
\hline Worker & 4.2 & 0.35 & $\begin{array}{l}\text { Protect on-site personnel from hazards and } \\
\text { accidental releases of waste and pollution by } \\
\text { ensuring maximum application of intrinsic safety } \\
\text { features. }\end{array}$ \\
\hline Permitting & 4.3 & 0.20 & $\begin{array}{l}\text { Minimize waste generation risk and difficulty of } \\
\text { permitting new releases and waste forms. }\end{array}$ \\
\hline
\end{tabular}




\section{Table 8 - Titles, Definitions, and Weights of Evaluation} Criteria Utilized in Phase II (con't)

\begin{tabular}{|c|c|c|c|}
\hline Criterion Title & $\begin{array}{c}\text { Criterion } \\
\#\end{array}$ & $\begin{array}{c}\text { Assigned } \\
\text { Weight }\end{array}$ & Definition \\
\hline Engineering (Design) & 5.0 & 0.20 & $\begin{array}{l}\text { Maximize the confidence that the facility meets } \\
\text { applicable codes, standards, and required production } \\
\text { throughput. }\end{array}$ \\
\hline Construct & 5.1 & 0.25 & $\begin{array}{l}\text { Ensure facility design considers major construction/ } \\
\text { testing methods and needs in accordance with } \\
\text { Integrated Work Process (IWP) and Key Activities } \\
\text { for Successful Execution (KASE). }\end{array}$ \\
\hline Qualify & 5.2 & 0.25 & $\begin{array}{l}\text { Readily validate defined functional design } \\
\text { requirements, regulatory requirements, final disposal } \\
\text { forms, and Authorization Basis (AB) safety } \\
\text { requirements. }\end{array}$ \\
\hline Operate & 5.3 & 0.25 & $\begin{array}{l}\text { Maximize ease of repeat operation/ } \\
\text { proceduralization, access for round sheets/ physical } \\
\text { verification, and upset operations management } \\
\text { (Section R-1.4-3 of Functions \& Requirements). }\end{array}$ \\
\hline RAMI & 5.4 & 0.25 & $\begin{array}{l}\text { Design to maximize Reliability, Availability, } \\
\text { Maintainability, and Inspectability }\end{array}$ \\
\hline Cost/Schedule & 6.0 & 0.12 & $\begin{array}{l}\text { Meet minimum combination of programmatic and } \\
\text { technical risks and life cycle costs. }\end{array}$ \\
\hline $\begin{array}{r}\text { Regulatory Schedule } \\
\text { Commitments }\end{array}$ & 6.1 & 0.50 & $\begin{array}{l}\text { Maximize capability of disposing of radioactive } \\
\text { wastes per Federal Facility Agreement (FFA) and } \\
\text { Site Treatment Plan (STP) schedules or earlier. }\end{array}$ \\
\hline Life Cycle Costs (LCC) & 6.2 & 0.30 & $\begin{array}{l}\text { Minimize LCC including TEC, OPC, and D\&D } \\
\text { (excludes salvage and repository costs). }\end{array}$ \\
\hline Repository Costs & 6.3 & 0.20 & $\begin{array}{l}\text { Minimize cost for waste disposal off-site (Federal } \\
\text { Repository). }\end{array}$ \\
\hline
\end{tabular}




\subsection{Utility Function Definition}

Each evaluation criterion was assigned three or more "utility functions" (UF). Utility functions provide a means of objectively grading an alternative against the applicable evaluation criterion. These functions described the most desirable end state down to the least desirable end state that the alternative(s) would exhibit on a scale of 0-100. Additional information can be found in HLW-SDT-980019, "Results Report on Utility Function Evaluation" (Reference 10).

\section{$\underline{13.4 \quad \text { Evaluation Process }}$}

Two methods were used for the evaluation: a horizontal review and a vertical slice. The horizontal review evaluated each Initial List alternative across all evaluation criteria. The vertical slice evaluated all eighteen Initial List alternatives against each evaluation criterion. Additional information on evaluation criteria and utility functions can be found in HLW-SDT-980019, "Results Report on Utility Function Evaluation" (Reference 10).

The following material was used during the formal evaluation process:

- Process Flow Diagrams

- Preconceptual Preliminary Risk Assessment Identification Forms

- Graphical and tabular results of the risk assessment information

- Preliminary Life Cycle Cost estimates

- Trip Reports from field confirmation visits

- Evaluation Criteria Assessment Form package

- Flowsheet Bases and Definition Document

An overview of each alternative Process Flow Diagram was provided by a Flow Sheet Task Team member to explain the assumed flowrates, chemistry specifics, and canister and saltstone production estimates, where applicable. The Team discussed each alternative as it related to each of the evaluation criteria and the utility functions to assign the utility function value. For each utility function value, the basis for the assigned value was documented (Reference 10).

Following the horizontal review of the Initial List alternatives, the Team performed a vertical slice evaluation for each evaluation criterion. The Team compared the utility function values and explanatory notes assigned during the horizontal review for each of the eighteen alternatives to ensure consistency in assignment. The data were revised if inconsistencies were found. The final utility function values and explanatory notes were used as input for the Short List alternative selection.

At the conclusion of the horizontal review and vertical slice of the main alternatives, variations of the main alternatives were evaluated to determine potential improvements in the evaluation. The variations 
were developed through the initial evaluation of the original Pro-Formas received in Phase I, new ProFormas received during Phase II, and changes to flowsheets identified by the Team to improve viability of the alternative. The variations were screened to determine if an improvement in the evaluation for the main alternative would occur due to the variation. The results of the screening are documented on the Alternative Variation Review Forms found in Reference 10. For those variations where an expected net improvement for the alternative was identified, the variation was re-evaluated and the results were used in the selection process to reach the Short List of alternatives.

\subsection{Sensitivity Analysis}

The sensitivity analysis was performed for the Phase II evaluation criteria weights, utility function values, and the total utility scores for each Initial List alternative. This analysis was performed to determine the sensitivity of the Initial List alternatives to uncertainty and/or bias in the weighting criteria and utility function values. This analysis also was used to verify the consistency in the scoring order of the alternatives using the utility function values.

Additional information can be found in WSRC-TR-98-00236, "Sensitivity Analysis of Alternative Methods for Disposition of High Level Salt Waste: A Position Statement (U)" (Reference 27) and WSRC-TR-98-00240, "Results Report on Sensitivity Analyses for Initial List Alternatives" (Reference 28).

Direct Disposal of Grout, Small Tank TPB, Zeolite Ion Exchange - DWPF Vitrification, Crystalline Silicotitanate (CST) Ion Exchange - DWPF Vitrification, and Caustic Side Solvent Extraction - DWPF Vitrification were determined to be robust to perturbations in the utility function values and evaluation criteria weights. These alternatives are in the top six for three of the four simulations. The robustness of these alternatives was confirmed through the analyses of scoring order and indicated that $10 \%$ changes in the weighting criteria or 20 unit changes in utility function values had no significant impact on their order. The results validated the Utility Function Evaluation performed by the Team.

\section{$\underline{13.6}$ Evaluation Results}

The total scores for each of the alternatives on the Initial List and their variations are provided in Tables 9 and 10 , along with the weighted score by evaluation criterion. 
Table 9: Weighted Evaluation Scores for the Initial List Alternatives

\begin{tabular}{|c|c|c|c|c|c|c|c|c|}
\hline & & Technology & $\begin{array}{l}\text { Current } \\
\text { Missions }\end{array}$ & $\begin{array}{l}\text { Future } \\
\text { Missions }\end{array}$ & Regulatory & Eng. & $\begin{array}{l}\text { Cost / } \\
\text { Schedule }\end{array}$ & \\
\hline Alt & Title & 1.0 & 2.0 & 3.0 & 4.0 & 5.0 & 6.0 & Total \\
\hline 1 & $\begin{array}{l}\text { Fractional Crystallization - DWPF } \\
\text { Vitrification }\end{array}$ & 11.50 & 08.96 & 04.90 & 15.41 & 09.00 & 08.10 & 57.87 \\
\hline 2 & $\begin{array}{l}\text { Electrochemical Separation and } \\
\text { Destruction - DWPF Vitrification }\end{array}$ & 03.22 & 04.69 & 02.45 & 07.99 & 04.00 & 02.10 & 24.45 \\
\hline 3 & $\begin{array}{l}\text { Elutable Ion Exchange - DWPF } \\
\text { Vitrification }\end{array}$ & 11.96 & 10.61 & 04.90 & 07.71 & 12.00 & 10.68 & 57.86 \\
\hline 4 & $\begin{array}{l}\text { Potassium Removal followed by TPB } \\
\text { Precipitation }\end{array}$ & 09.20 & 06.94 & 02.45 & 05.52 & 09.50 & 09.30 & 42.91 \\
\hline 5 & $\begin{array}{l}\text { Acid-side Ion Exchange - DWPF } \\
\text { Vitrification }\end{array}$ & 10.81 & 10.39 & 04.90 & 05.75 & 11.00 & 10.50 & 53.35 \\
\hline 6 & $\begin{array}{l}\text { Crystalline Silicotitanate (CST) Ion } \\
\text { Exchange - DWPF Vitrification }\end{array}$ & 18.86 & 11.48 & 04.90 & 11.56 & 11.50 & 10.86 & 69.16 \\
\hline 7 & $\begin{array}{l}\text { Crystalline Silicotitanate (CST) Ion } \\
\text { Exchange - New Facility Vitrification }\end{array}$ & 19.32 & 13.09 & 02.45 & 13.11 & 13.75 & 4.20 & 65.92 \\
\hline 8 & $\begin{array}{l}\text { Zeolite Ion Exchange - DWPF } \\
\text { Vitrification }\end{array}$ & 18.86 & 09.15 & 04.90 & 17.82 & 12.00 & 07.92 & 70.65 \\
\hline 9 & $\begin{array}{l}\text { Crystalline Silicotitanate (CST) Ion } \\
\text { Exchange - Ceramic Waste Form }\end{array}$ & 13.57 & 13.39 & 02.45 & 12.88 & 15.50 & 04.56 & 62.35 \\
\hline
\end{tabular}


Table 9: Weighted Evaluation Scores for the Initial List Alternatives (con't)

\begin{tabular}{|c|c|c|c|c|c|c|c|c|}
\hline & & Technology & $\begin{array}{l}\text { Current } \\
\text { Missions }\end{array}$ & $\begin{array}{l}\text { Future } \\
\text { Missions }\end{array}$ & Regulatory & Eng. & $\begin{array}{l}\text { Cost / } \\
\text { Schedule }\end{array}$ & \\
\hline Alt & Title & 1.0 & 2.0 & 3.0 & 4.0 & 5.0 & 6.0 & Total \\
\hline 10 & Reduced Temperature ITP & 10.58 & 08.36 & 02.45 & 10.52 & 04.50 & 10.20 & 46.61 \\
\hline 11 & Catalyst Removal ITP & 11.04 & 08.21 & 02.45 & 10.52 & 13.00 & 10.20 & 55.42 \\
\hline 12 & ITP with Enhanced Safety Features & 08.74 & 07.50 & 02.45 & 07.82 & 04.50 & 9.84 & 40.85 \\
\hline 13 & Small Tank TPB & 19.32 & 10.28 & 04.90 & 15.18 & 13.00 & 10.20 & 72.88 \\
\hline 14 & Caustic Side Solvent Extraction & 14.95 & 11.14 & 04.90 & 13.17 & 15.50 & 09.48 & 69.14 \\
\hline 15 & Acid Side Solvent Extraction & 18.40 & 10.16 & 04.90 & 04.08 & 14.25 & 08.40 & 60.19 \\
\hline 16 & Direct Vitrification & 05.98 & 06.11 & 00.00 & 09.89 & 05.50 & 02.40 & 29.88 \\
\hline 17 & $\begin{array}{l}\text { Supernate Separation - DWPF } \\
\text { Vitrification }\end{array}$ & 14.72 & 02.17 & 03.15 & 11.73 & 14.00 & 02.16 & 47.93 \\
\hline 18 & Direct Disposal Grout & 22.54 & 14.14 & 02.45 & 18.63 & 19.50 & 06.60 & 83.86 \\
\hline
\end{tabular}


Table 10: Level 1 Weighted Scores for Alternative Variations

\begin{tabular}{|c|c|c|c|c|c|c|c|c|}
\hline & & Technology & $\begin{array}{l}\text { Current } \\
\text { Missions }\end{array}$ & $\begin{array}{l}\text { Future } \\
\text { Missions }\end{array}$ & Regulatory & Eng. & $\begin{array}{l}\text { Cost / } \\
\text { Schedule }\end{array}$ & \\
\hline Alt & Title & 1.0 & 2.0 & 3.0 & 4.0 & 5.0 & 6.0 & Total \\
\hline 1.C & $\begin{array}{l}\text { Use barium to remove chromate and reduce number } \\
\text { of canisters }\end{array}$ & 11.50 & 11.03 & 04.90 & 18.46 & 09.00 & 08.22 & 63.10 \\
\hline $\begin{array}{l}11 . \\
D\end{array}$ & $\begin{array}{l}\text { Add additional Engineered Safety Features and fix } \\
\text { Late Wash Facility throughput }\end{array}$ & 05.29 & 08.21 & 02.45 & 11.04 & 06.25 & 10.02 & 43.26 \\
\hline $\begin{array}{l}15 . \\
\mathrm{C}\end{array}$ & $\begin{array}{l}\text { Alternate diluent, NOx abatement and organic } \\
\text { removal }\end{array}$ & 13.80 & 10.39 & 04.90 & 11.50 & 13.25 & 08.40 & 62.24 \\
\hline 3.E & $\begin{array}{l}\text { Add nitrate destruction to resolve DWPF (F-N) } \\
\text { problem and add NOX abatement }\end{array}$ & 11.73 & 10.99 & 04.90 & 10.47 & 12.75 & 10.68 & 61.51 \\
\hline 5.B & Add NOX abatement & 10.81 & 10.39 & 04.90 & 08.51 & 11.00 & 10.32 & 55.93 \\
\hline 6.D & Pump pit installation for CST (sensitivity) & 18.86 & 11.48 & 04.90 & 11.56 & 11.50 & 11.40 & 69.69 \\
\hline 7.C & $\begin{array}{l}\text { DWPF "campaign" could be employed instead of } \\
\text { the new facility vitrification }\end{array}$ & 18.40 & 10.91 & 04.90 & 15.41 & 11.25 & 10.14 & 71.01 \\
\hline 7.D & Send glass to Federal Repository & 19.32 & 13.09 & 04.90 & 15.41 & 13.75 & 10.08 & 76.55 \\
\hline $9 . \mathrm{B}$ & $\begin{array}{l}\text { Other alternatives for resin storage are possible, e.g. } \\
\text { make the ceramic in DWPF type canisters and store } \\
\text { in GWSB until ready for disposal in a Federal } \\
\text { Repository }\end{array}$ & 13.57 & 13.39 & 04.90 & 13.57 & 15.50 & 08.64 & 69.57 \\
\hline
\end{tabular}




\subsection{Team Decision Process}

The Summary Reports for the different Phases of the Team efforts go into significant detail on individual Team activities with full documentation. With the presentation of this level of information, it can be difficult to follow the outline and intent of the Team decision process. The following provides a high level overview of the form and intent of the process.

The Team has been charged with the mission of reviewing potential salt disposition technologies and recommending a preferred technology (ies) for implementation at SRS to close the remaining waste storage tanks in accordance with the existing STP and FFA requirements.

The method chosen to accomplish this mission must reflect a number of attributes. The process must be wide-ranging, objective, thorough, rigorous and well documented. It must be open to and seek out the best ideas of the DOE complex, academia and industry and stay open to such input throughout the selection period. In support of these attributes, the Systems Engineering approach was chosen and a Systems Engineering Team composed of diverse, multi-disciplined, highly qualified members was selected and dedicated to the effort. In turn, the Team chose to develop flowsheets for candidate technologies, which were sufficiently detailed to support a rigorous and objective evaluation of the technologies. A structured, multi-attribute utility analysis model was applied during the evaluation.

This mission involves several discrete tasks that can be summarized as follows:

1. Survey current industrial, academic and government knowledge to determine potential technologies for this application

2. Express the technical concepts identified by the survey in terms of potential engineering applications to meet the SRS need

3. Apply a coarse screen to identify the processes with a real likelihood of successful application at SRS

4. Develop further information on the identified processes in terms of technological, safety, cost and schedule and interface risk to establish a Short List of potential processes for detailed study

5. Perform a program to define in more detail the costs, risks and potentials of each of the Short List candidates

6. Take into account all constraints, such as the need to meet the FFA deadline of 2028 for closing tanks, not generate waste streams with no known disposition, and compatibility with SRS wastes

7. Based on the information developed throughout the program, propose the preferred technology(ies)

8. Propose an implementation strategy which minimizes project risk 
Some major challenges which must be addressed in completing the mission are:

1. Overlooking promising technologies through an overly narrow search

2. Eliminating candidate technologies through over- or under-valuing certain attributes

3. Propagating unworthy candidates by misvaluing important attributes

4. Eliminating promising technological applications through failure to adjust engineering implementation to address identified issues

5. Expending unnecessary resources on candidate technologies containing "fatal flaws"

The Team has developed a process to accomplish the required tasks implementing the Systems Engineering approach while meeting the identified challenges.

\subsection{Process Development}

The Team recognized that its application of the Systems Engineering process would have to address two steps. Those two steps are: (1) the identification of a pool of potentially successful solutions; and, (2) the selection of the preferred approach from that pool. Frequently, a collection of potentially successful applications is available at the start of the effort and the necessary task is merely to select the best alternative from a group which all are acknowledged to be technically and programmatically acceptable.

The Team charter requires it to establish acceptability of the candidates as part of the selection process. The Systems Engineering method developed by the Team accomplishes the two goals by varying the emphasis placed on the objectives throughout the duration of the effort. Early in the process the primary effort related to identifying technical concepts and only eliminated those with obvious "fatal flaws." Late in the process a small number of well defined (at the preconceptual level) engineering applications with very high likelihood of technical success will be compared with regard to technical, business and management attributes to establish the alternative(s) most suited for implementation. During all phases, the Systems Engineering process must be open to full consideration of newly identified candidate technologies.

A successful transition from the high level conceptualization and information gathering of the early part of the process to the focussed, detailed, review of the late portion is highly dependent on the decisions and information development undertaken in the middle portion of the process. The product of this part of the process is the definition of a small number of processes with high likelihood of successful implementation. Inherent in the development of such a list is the need to determine and roughly quantify the technical, design, operations, interface, safety, cost and schedule risks of the candidate technologies, to identify the preferred engineering implementation for the concepts and to discard those concepts which clearly have fatal flaws or are clearly inferior to the surviving candidates. 
The keynote difficulty to be addressed by the middle phase of the process is to identify an engineering implementation for each candidate technology for comparison purposes which remains open to documented modifications reflecting the best implementation of each technology. The process addresses this difficulty by establishing key decision points, at which times defined and documented changes are permitted to the engineering implementations to address identified weaknesses. The costs (both with regard to resources and project risk) and benefits associated with the changes are incorporated into the evaluation of the candidate technology. The Team explicitly chose not to drop any candidate from consideration prior to such a decision point. The logic for this rule was that the entire period should be available to consider remedies for the flaw and that efforts to address the flaw might spin off ideas beneficial to other candidates.

The overall Preconceptual process is shown in Figure 5.

\subsection{Phase I (Identification)}

The purpose of Phase I of the process is to establish a comprehensive list of candidate technologies and to identify a working list of the technologies which, at a high level, appear capable of being successfully deployed on the required time scale. In this phase, the emphasis is on completeness. All decisions are structured to avoid premature technology elimination and to err on the side of over-inclusion.

This phase began with a Team effort to establish and communicate the functions and requirements to be accomplished by the eventual preferred technology(ies). Based on the defined functions and requirements, a request for proposed technologies was spread widely across the Savannah River Site, the DOE complex, academia and industry. This request was supplemented by brainstorming sessions with invited experts. A longer-term literature search was initiated at this time utilizing the resources of the Savannah River Technical Center, the Oak Ridge National Laboratory and the Pacific Northwest National Laboratory to assure that potentially successful technologies were not overlooked.

The Phase I decision making process (Reference 8) was designed to act as a coarse sieve to eliminate concepts which could clearly not be relied on to be successful on the required time scale and to provide an opportunity to mix and match fragmentary and/or complete technology concepts and potential engineering implementations to create processes with the potential to meet the functions and requirements earlier defined. The Team developed a number of suggestions reflecting combinations of submitted ideas for further consideration as a result of this process. 
Figure 5: Preconceptual Process

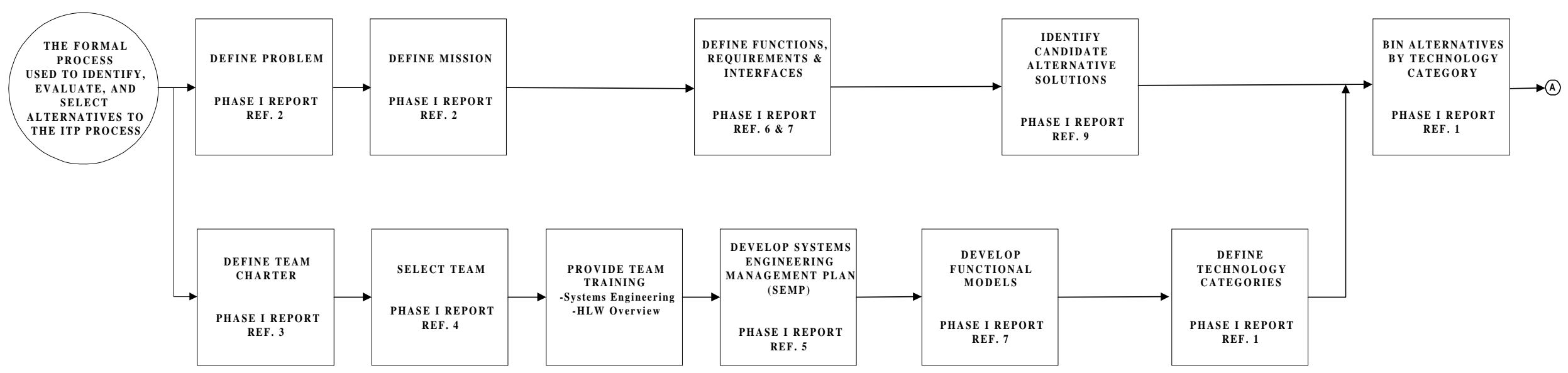




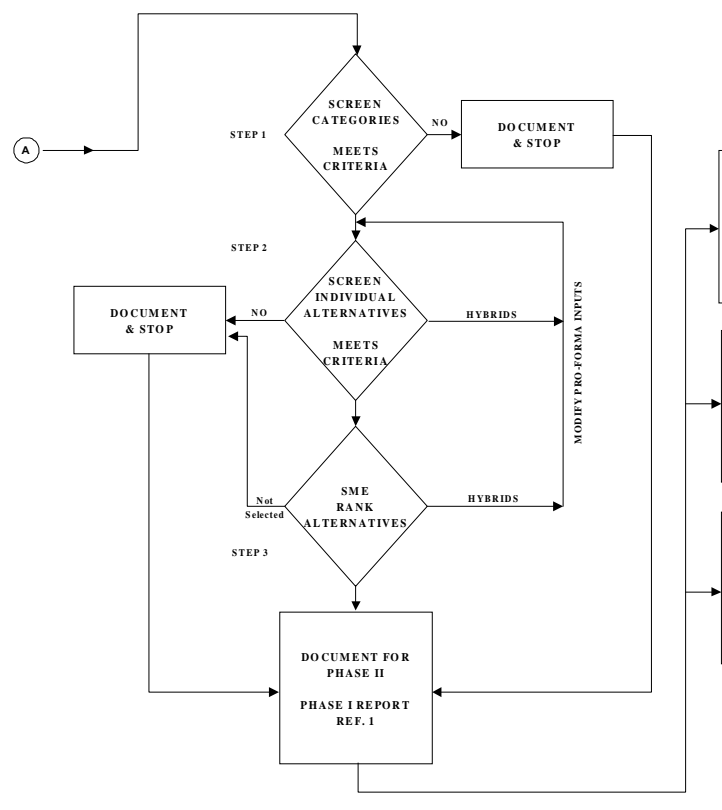

\section{Figure 5: Preconceptual Process}

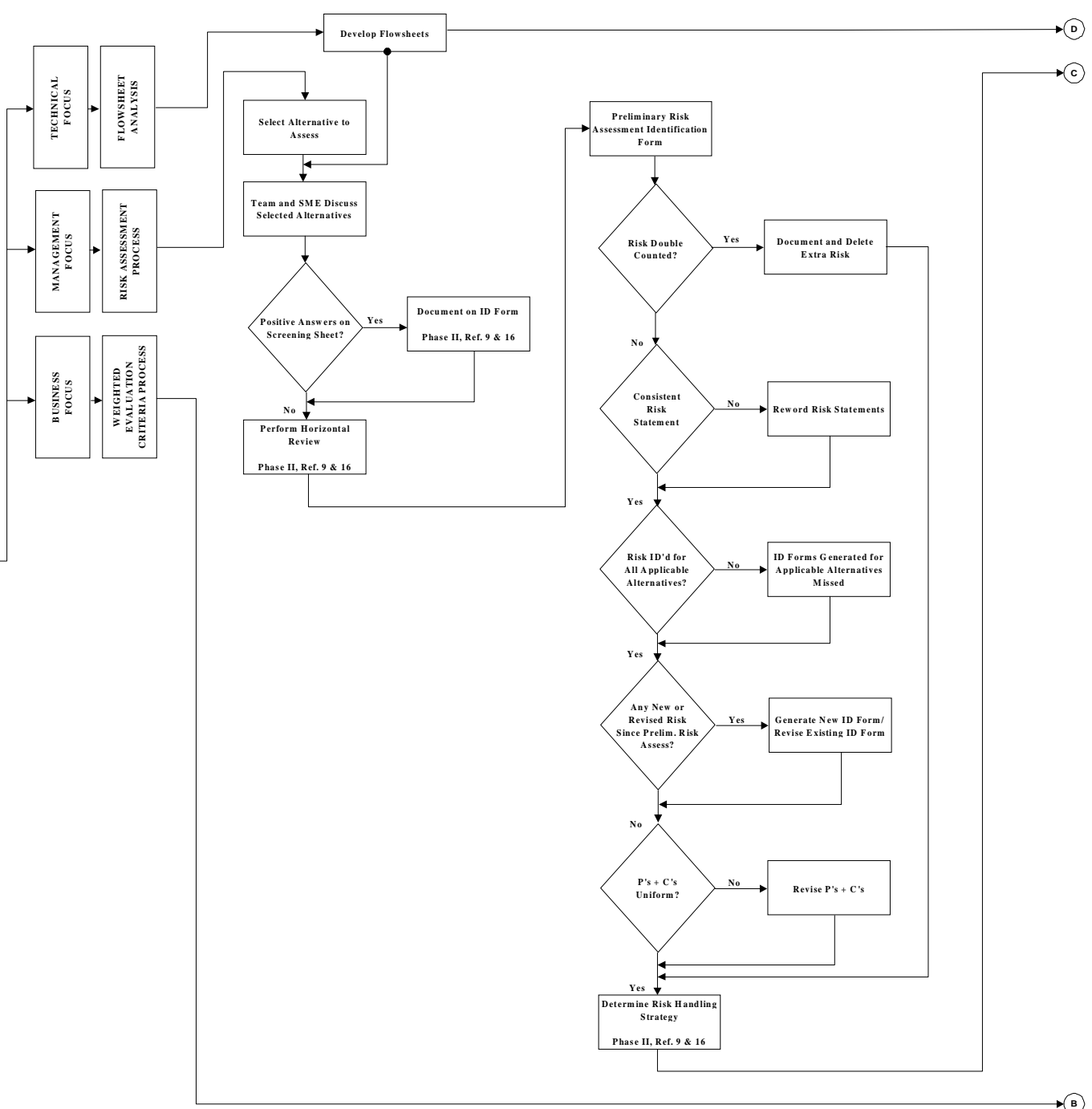


Figure 5: Preconceptual Process

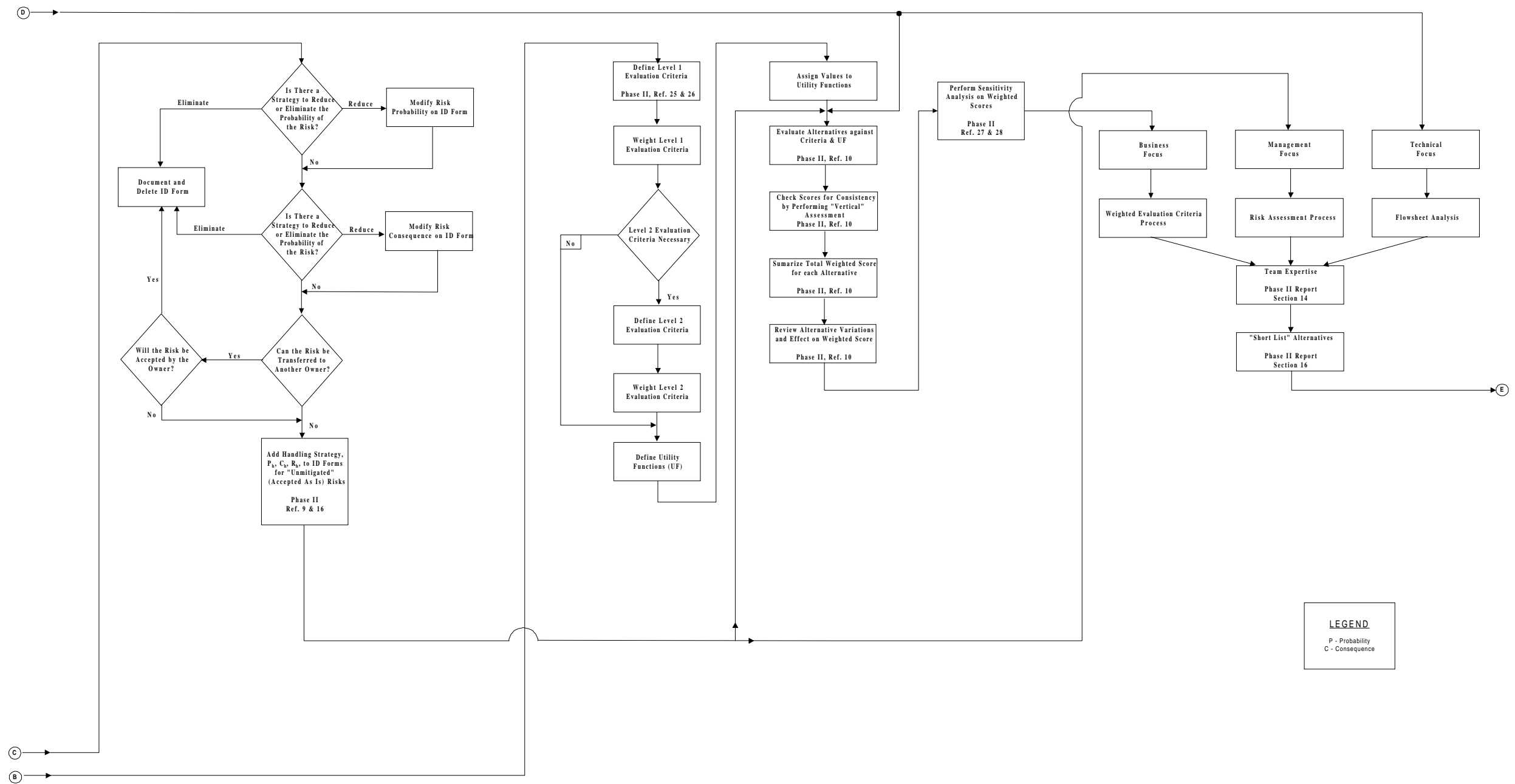




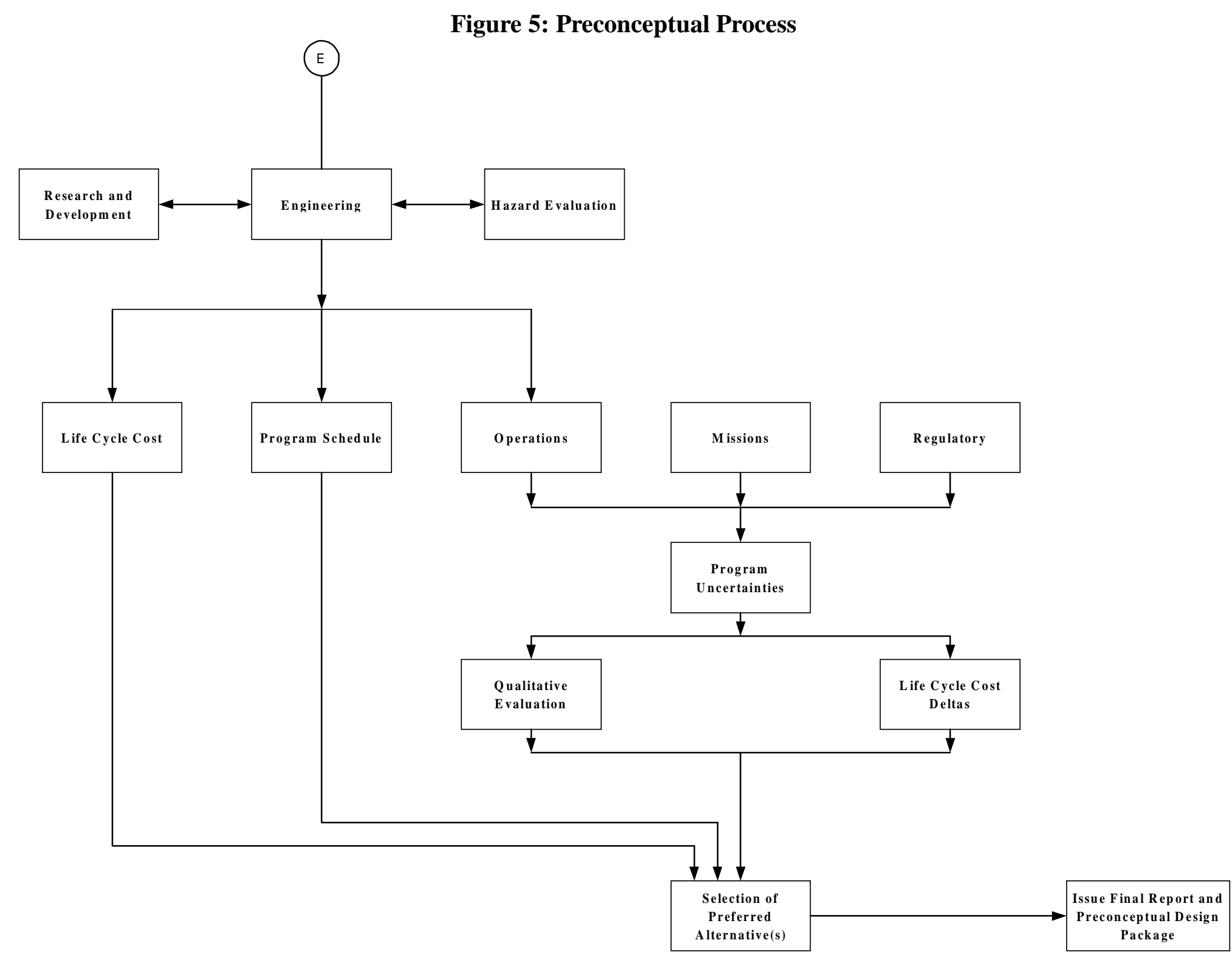


The decision making in this phase was not intended to eliminate concepts from consideration but to find concepts suitable for further consideration. This intent is reflected by the fact that only a small minority of the suggested solutions was completely dropped from consideration. The great bulk (approximately 64\%) of the suggestions were either carried forward to Phase II, considered to be included within individual Phase II Initial List alternatives, carried as a variation of a Phase II Initial List alternative or used to create a new potential solution. Suggestions were only eliminated from further consideration if they were clearly not capable of successful implementation within the needed functions and requirements, could not be reliably deployed on the required time scale due to scientific or engineering immaturity, or were clearly inferior to similar technologies (e.g., if multiple ion exchange resins were available which could all remove cesium, only the best one(s) would be carried forward). Since the Team had knowledge of the dropped suggestions, they could bring them back later if the preferred suggestions proved to have major flaws.

The product of this phase was a list of eighteen alternatives, each with a textual description, a high level flowsheet and a number of identified variations. These alternatives were carried forward for further consideration in the next phase.

Table 11 was prepared from References 14 and 30 through 33 and personal communications. It compares the options considered by the SRS process to a high level survey of those identified in recent similar DOE Complex programs (West Valley, INEEL, Oak Ridge, and Hanford). While the outcomes vary from site to site depending on waste composition, site specific legislation and other unique site considerations, it is clear that the SRS process has not overlooked technologies considered important at other sites and that options considered important in those studies have been given strong consideration by the SRS Systems Engineering Team. While not shown in the table, the Team also reviewed technologies in use or under development in other countries, e.g. grout application by BNFL. 
Table 11: DOE Complex Technology Review Comparison

\begin{tabular}{|c|c|c|c|c|c|}
\hline Alternative & SRS & WVNS & ORNL & INEEL & Hanford \\
\hline Fractional Crystallization & A & & & & $\mathrm{X}$ \\
\hline Crystalline Silicotitanate (CST) & A & & $\mathrm{X}$ & $\mathrm{X}$ & $\mathrm{X}$ \\
\hline $\begin{array}{l}\text { Zeolite (Non-elutable Ion } \\
\text { Exchange) }\end{array}$ & $\begin{array}{c}\mathrm{K} 2 \mathrm{CoFe}[\mathrm{CN}] 6 \\
\text { A } \\
\text { Durasil }\end{array}$ & $\mathrm{X}$ & $\mathrm{K} 2 \mathrm{CoFe}[\mathrm{CN}] 6$ & $\mathrm{~K} 2 \mathrm{CoFe}[\mathrm{CN}] 6$ & \\
\hline Elutable Ion Exchange & A & $\begin{array}{l}\text { CS-100 } \\
\text { (Duolite) }\end{array}$ & $\begin{array}{c}\text { RF } \\
\text { SuperLig } \\
\text { CS-100 }\end{array}$ & AMP-PAN & $\begin{array}{c}\text { SuperLig } \\
\text { Duolite, RF } \\
\text { X }\end{array}$ \\
\hline Acid Side Ion Exchange & A & & & AMP-PAN & \\
\hline Tetraphenylborate Precipitation & A & $\mathrm{X}$ & & & $\mathrm{X}$ \\
\hline Caustic Side Solvent Extraction & A & & & & $\mathrm{X}$ \\
\hline Acid Side Solvent Extraction & A & & & $\mathrm{X}$ & \\
\hline Electrochemical & A & $\begin{array}{c}\text { Electrodialysis } \\
\mathrm{X}\end{array}$ & & $\mathrm{X}$ & \\
\hline Direct Vitrification & A & Reject-WVDA & & & $\mathrm{X}$ \\
\hline Direct Grout & A & Reject-WVDA & Prohibited by State & & $\begin{array}{l}\text { X Not Allowed per } \\
\text { Tri-Party Agreement }\end{array}$ \\
\hline Supernate Separation & A & & & & $\begin{array}{l}\text { Saltwell Pumping } \\
\text { Utilized }\end{array}$ \\
\hline Hyperfiltration & $\mathrm{R}$ & $\mathrm{X}$ & & & \\
\hline Other Precipitation & & $\begin{array}{l}\text { K2CoFe[CN]6 } \\
\text { Na2NiFe[CN]6 } \\
\text { PTA }\end{array}$ & & & $\begin{array}{l}\mathrm{K} 2 \mathrm{CoFe}[\mathrm{CN}] 6 \\
\text { Na2NiFe[CN]6 } \\
\text { PTA }\end{array}$ \\
\hline Biosorbants & $\mathrm{R}$ & $\mathrm{X}$ & & $\mathrm{X}$ & $\mathrm{X}$ \\
\hline $\begin{array}{l}\text { Chelating Agents (Devoe - } \\
\text { Holbein) }\end{array}$ & $\mathrm{R}$ & $\mathrm{X}$ & & & $\mathrm{X}$ \\
\hline
\end{tabular}

$\mathrm{A}=$ Accepted as an alternative

$\mathrm{R}=$ Rejected

$\mathrm{X}=$ Addressed

WVDA $=$ West Valley Demonstration Act

PTA $=$ Phosphotungstic Acid

$\mathrm{RF}=$ Resorcinal Formaldehyde

AMP-PAN $=$ Ammonium molybdophosphate - Polyacrylonitrile 


\subsection{Phase II (Investigation)}

The middle phase of the decision making process is intended to develop information regarding the strengths and weaknesses of concepts under consideration and to sharpen the definition of the engineering implementation of the concepts. It provides the transition from the early searches for concepts that might work, to the later detailed comparative review of developed engineering solutions. The emphasis is on acquiring a better understanding of the strengths and weaknesses of the concepts and their engineering implementations. Decisions in this phase are intended to be conservative, but to support making realistic choices, based on developed data, about the potential for successful implementation of the alternatives.

This phase began with creation by the Team of a risk assessment structure to provide a framework for exploration of the Initial List alternatives. Risk areas for consideration were defined. These areas covered technical, management and business aspects of the alternatives. The Team, with the assistance of additional subject matter experts, then created a list of applicable risks for each alternative within these areas. Rough values were assigned to risks to help calibrate the magnitude of concern represented by each risk. Consistency of application and weighting was assured by a "Horizontal" review of the risks across all the alternatives. This assured that individual risks applicable to a number of Alternatives were applied uniformly and that consistent weights were assigned over the two-week process. A detailed overview of this process is provided in Reference 16.

The risks identified were then used, along with a number of other inputs such as material balance based flowsheets, knowledge of operating facilities and experimental results, as the basis for a ranking process of the alternatives. Each Initial List alternative was assigned a score between 0 and 100 in the areas of Technology, Current Mission Interfaces, Future Mission Interfaces, Regulatory/ISMS/ Environmental, Engineering (Design), and Cost/Schedule. These areas were weighted by importance in this Phase, emphasizing Technology, Regulatory/ISMS/Environmental and Engineering (Design). An overall assessment of the alternatives against these criteria resulted from this effort. Reference 25 describes this activity.

It should be noted that this process used a different weighting of Alternative attributes than will likely be used in later activities. The process has carried forward to this stage alternatives which may or may not be technically capable of successful implementation. The process has not permitted Initial List alternatives to be eliminated due to lack of information, only if information exists to show that the concept is not feasible. It is therefore important at this stage to determine which of the alternatives can be reasonably implemented. Later, choices can be made among the technically feasible alternatives with the emphasis on cost and schedule. At this stage there is no value in crediting an alternative for high potential in cost and schedule performance if it simply will not work if implemented. 
In parallel with this process, the Team commissioned a statistical sensitivity study of the weights and benchmarks. This sensitivity study facilitated a review of the process to see if scorings (either high or low) were merely artifacts of the process rather than a true reflection of the merit of the alternatives. This was not expected to impact either the highest or lowest scoring alternatives since an alternative that scores high in all areas or low in all areas is insensitive to weighting. There could however have been an impact on marginal candidates for consideration in the final phases.

Completion of the scoring process and sensitivity study permitted the selection of the Short List for Phase III consideration. The selection process drew heavily on the data generated in all of the preceding activities. There were four major considerations within the selection:

1) Does an Alternative have a Fatal Flaw?

2) Does an Alternative have high potential for successful implementation, as reflected in its ranking score?

3) Is an Alternative similar to but inferior to another Alternative?

4) Is there a Variation of the defined Alternative, which would resolve weaknesses otherwise, causing the Alternative to have a Fatal Flaw or low potential?

The product of this selection was the identification of the group of technologies that have a realistic chance, based primarily on technology, engineering, safety, and compatibility with Site missions, of being implemented. These technologies were carried forward for detailed consideration.

\subsection{Phase III (Selection)}

The purpose of Phase III is to select the preferred alternative(s) for implementation at SRS for High Level Waste Salt Disposition. In this phase the emphasis is on analyzing the comparative merits and weaknesses of technologies and their associated engineering which are known to have a high probability of successful deployment in this application, with regard to cost. All decisions in this phase are structured to make the best use of available and developed information to make a final selection.

Phase III will begin with a Team effort to build upon Phase II risks and identify additional risks. Risks will be analyzed to determine if they have the potential to result in cost and/or schedule uncertainties in the implementation of the alternatives. Design input associated with identified risks will be documented. Simultaneously, a flowsheet engineering team will initiate more detailed modeling of the proposed processes to develop engineering detail of how the candidate technologies would be implemented, leading to the production of preconceptual design information. Also, targeted research and development tasks with a short turnaround time will be commissioned to investigate issues that can be resolved or better defined through a short research program. 
The Phase III selection process will differ from that of Phase II in its emphasis. The Phase II process was used to establish the candidates that had the best chance of success from a technology, design, safety or interface point of view. Since Short List candidates are acceptable in these categories, cost performance now becomes the major discriminator.

The Team will use a standard cost and schedule uncertainty tool e.g. Monte Carlo simulation. Additional uncertainties will be applied by the Team in a quantitative and qualitative manner for positive and negative impacts on costs. Some of the categories for uncertainty application include:

- Mission

- Technical maturity

- Environmental

- Engineering/Design

- Operation

- Regulatory

- Stakeholder

- Safety

- Radiological

1) Following completion of the identification and application of cost uncertainties to the estimating process, the Team will review the results of the process in order to select the preferred alternative(s).

As with the Phase II selection process, it is not necessary to ask if unevaluated candidates would have qualified since all new candidates which emerge prior to Team delivery of its final deliverables are required to be evaluated through the process as far as the merits of the technology carry it.

The selected alternative(s) will be developed through preconceptual design. 


\subsection{Dissenting Opinions}

The Team evaluation and decision process was based upon consensus between Team members. To support this approach, a formal dissenting opinion process was established to allow any Team member to go on record as not agreeing with a Team decision. A dissenting opinion represents disagreement, on the part of one or more Team members, with a documented detail, conclusion or other written information that will be used in the eventual selection or rejection of an alternative solution.

Dissenting opinions can be submitted in written form to the Team Leader with a unique identifying number to allow tracking of the issue.

There were no dissenting opinions in Phase I or Phase II of the process.

Additional information on the dissenting opinion process can be found in HLW-SDT-980005, "Position Paper on Identifying \& Documenting Dissenting Opinions in the Evaluation and Selection of Alternatives to the In-Tank Precipitation Process" (Reference 29). 


\section{$\underline{16.0}$ Conclusions}

The structured Systems Engineering approach utilized by the Team successfully facilitated the identification and evaluation of a wide range of alternatives for SRS HLW salt disposition. The evaluation considered approximately 140 identified alternatives and resulted in an Initial List of 18 alternatives for further evaluation in Phase II.

The Team evaluated each of the Initial List alternatives to determine the Short List for further evaluation in Phase III. This evaluation included facets of a Business Focus, Management Focus, and Technical Focus as shown in Figure 6. The Team used numerous information sources such as flowsheets, life cycle costs, and subject matter expert input to score the alternatives using a weighted evaluation process. A weighted evaluation process supported the Business Focus of the decision process. The preliminary risk assessment performed by the Team determined potential risk in areas such as Safety, Regulation and Environment, and Facility Interfaces. This risk information provided the information that supported the Management Focus of the decision process. The data tables and Process Flow Diagrams developed for each alternative provided the technical information such as material balances, chemical interactions, and process output. This information was critical to support the Technical Focus of the decision process. The Team used its expertise to combine these components of Business, Management, and Technology aspects to rank the alternatives and to determine the Short List of alternatives.

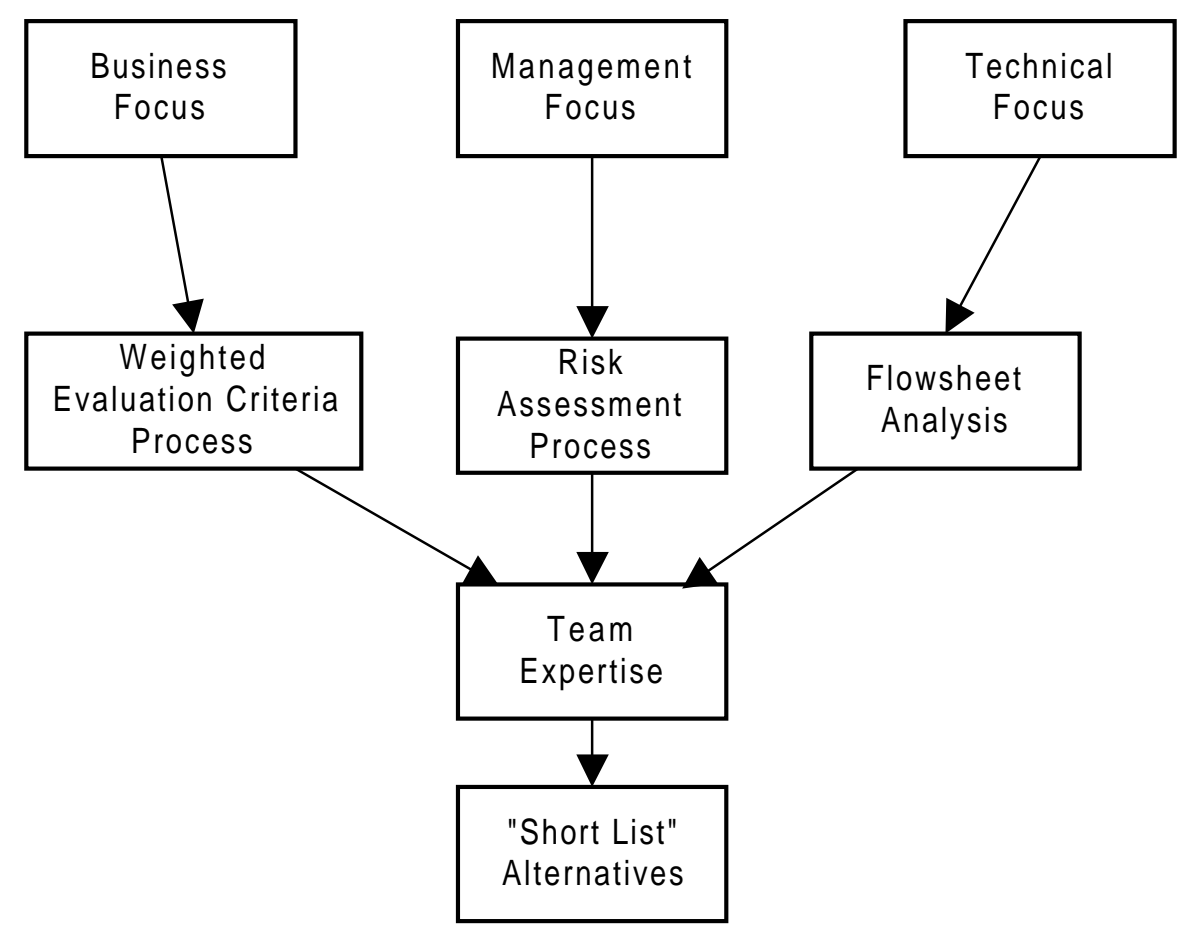

Figure 6: Down Select Process 


\subsection{Short List Alternatives}

The alternatives shown in Table 12 were chosen for further evaluation during Phase III of the Systems Engineering process.

Table 12: Short List Alternatives

\begin{tabular}{|c|c|}
\hline \multirow[t]{2}{*}{ Direct Disposal as Grout } & $\begin{array}{ll}\text { - } & \text { Simple Process } \\
\text { - } & \text { Mature Technology } \\
\text { - } & \text { Low Cost } \\
\text { - } & \text { Ease of Operation }\end{array}$ \\
\hline & $\begin{array}{l}\text { Disadvantages: } \\
\text { - } \quad \text { Requires Confirmation of Non-Transuranic Salt as Incidental Waste } \\
\text { - } \quad \text { Does not Support the Can-in-Can Mission }\end{array}$ \\
\hline \multirow{2}{*}{$\begin{array}{l}\text { Non-elutable Ion Exchange } \\
\text { (CST-Vitrification is the preferred option) }\end{array}$} & \begin{tabular}{ll}
\multicolumn{1}{c}{ Advantages: } \\
- $\quad$ Inorganic Stable Resin \\
- $\quad$ Pilot and Production Nuclear Experience \\
- $\quad$ Fempatible with Existing Waste Streams and Glass \\
Ferations
\end{tabular} \\
\hline & $\begin{array}{l}\text { Disadvantages: } \\
\text { - } \quad \text { Slurry Handling Difficulties } \\
\text { - Glass Requalification }\end{array}$ \\
\hline \multirow[t]{2}{*}{ Small Tank TPB } & \begin{tabular}{ll}
\multicolumn{1}{c}{ Advantages: } \\
- & Demonstrated Technology \\
- & Simple Unit Operation \\
- & Small Footprint \\
- & Compatible with Existing Equipment and Infrastructure \\
& Addresses Large Tank Issues
\end{tabular} \\
\hline & $\begin{array}{l}\text { Disadvantages: } \\
\text { - } \quad \text { Salt Process Cell Complexity } \\
\text { - } \quad \text { Benzene Emissions Not Eliminated } \\
\text { Liquid Benzene Disposal }\end{array}$ \\
\hline \multirow[t]{2}{*}{ Caustic Solvent Extraction } & \begin{tabular}{ll} 
& \multicolumn{1}{c}{ Advantages: } \\
- & Mature Technology \\
- & Solvent Extraction SRS Operating Experience \\
- & Liquid System \\
- & Few Unit Operations \\
& Centrifugal Contactors Minimize Solvent Chemical and Radiation \\
& Damage
\end{tabular} \\
\hline & \begin{tabular}{ll}
\multicolumn{1}{c}{ Disadvantages: } \\
- & Extractant not Mature \\
- & Uses Organic Solvents \\
- $\quad$ Difficulty in Establishing Steady in Control of "Crud"
\end{tabular} \\
\hline
\end{tabular}


The alternatives shown in Table 13 are considered "Threshold Alternatives" because they fell in the next grouping of alternatives as ranked by the Team. These alternatives were further discussed to determine if one or more should be included in the Short List. The Team determined that these Threshold Alternatives would not be included in the Short List for further evaluation during Phase III.

\section{Table 13: Threshold Alternatives}

\begin{tabular}{|c|c|}
\hline \multirow[t]{2}{*}{ Acid Side Solvent Extraction } & \begin{tabular}{ll}
\multicolumn{1}{c}{ Advantages: } \\
- $\quad$ Mature Technology \\
- $\quad$ Solvent Extraction SRS Operating Experience \\
- $\quad$ Ligh Throughput Potential \\
- $\quad$ Centrifugal Contactors Minimize Solvent Chemical and \\
Radiation Damage
\end{tabular} \\
\hline & \begin{tabular}{ll}
\multicolumn{1}{c}{ Disadvantages: } \\
- & Toxic and Flammable Diluent \\
- & Uses Organic Solvents \\
- & Difficulty in Establishing Steady State Operation \\
- & Multiple Unit Operation \\
- & Requires Large Quantities of Strong Nitric Acid \\
- & Significant Saltstone Production Increase \\
- & High $\mathrm{NO}_{\mathrm{x}}$ Generation
\end{tabular} \\
\hline \multirow[t]{2}{*}{ Fractional Crystallization } & $\begin{array}{ll}\text { - } & \text { Advantages: } \\
\text { - } & \text { Inherent Safety } \\
\text { - } & \text { Primarily Pnit Operation } \\
\text { - } & \text { High Throughical Process } \\
\end{array}$ \\
\hline & \begin{tabular}{ll}
\multicolumn{1}{c}{ Disadvantages: } \\
- & Multiple Coupled Unit Operation \\
- & Large Footprint \\
- & Extremely Complex Operation \\
- & Difficulty in maintaining steady state operation
\end{tabular} \\
\hline \multirow[t]{2}{*}{ Elutable Ion Exchange (SuperLig) } & \begin{tabular}{ll}
\multicolumn{2}{c}{ Advantages: } \\
- & Mature Unit Operation \\
- & High Cesium Selectivity \\
- & Reusable Resin,
\end{tabular} \\
\hline & \begin{tabular}{ll}
\multicolumn{1}{c}{ Disadvantages: } \\
- & Immature Resin \\
- & Resin Swelling and Shrinking \\
- & Potential Resin Nitration \\
- & High Hydrogen Generation \\
- & Complex Resin Pre-treatment
\end{tabular} \\
\hline
\end{tabular}




\subsection{Phase III Start Criteria and Controls}

Phase III of the Salt Disposition Systems Engineering Process will focus on the final selection of a preferred alternative(s). Phase I concentrated on the identification of alternatives and Phase II on the technical investigation necessary to select the Short List.

The Phase III selection process encompasses a more detailed Life Cycle Cost Analysis and Uncertainty Evaluation to reflect Programmatic Risk.

The start for Phase III begins with concurrence of the selected alternatives by the Independent Review Team and the establishment of a formal change control process applied to technical, cost and schedule baselines. 


\subsection{References}

1. Defense Nuclear Facilities Safety Board (DNFSB) Recommendation 96-1.

2. HLW-OVP-98-0020, HLW Salt Disposition Systems Engineering Team Charter.

3. WSRC-TR-98-00181, Identification of Cesium Removal Technologies.

4. Candidate Selections for the HLW Salt Disposition Systems Engineering Team.

5. WSRC-RP-98-00163, Systems Engineering Management Plan for Development of Alternatives to Process and Dispose of High Level Waste Salt (U).

6. WSRC-TR-98-00164, High Level Waste Salt Disposition Interface Requirements.

7. Preconceptual-Phase I Initial Design Input, Revision Dated: 6/24/98.

8. High Level Waste Salt Disposition Systems Engineering Team Position Paper on the Evaluation Leading to the "Initial List" of Alternatives.

9. HLW-SDT-980015, Results Report on Preliminary Risk Assessment with Adjusted Risk Values.

10. HLW-SDT-980019, Results Report on Utility Function Evaluation.

11. HLW-SDT-980018, Results Report on Preliminary Life Cycle Cost Estimates for Initial List Alternatives.

12. WSRC-RP-98-00166, Bases, Assumptions, and Results of the Flowsheet Calculations for the Initial Eighteen Salt Disposition Alternatives.

13. SRT-WPT-98-008, Evaluation of Potential Cesium Removal Technologies (U)

14. WSRC-RP-98-00162, HLW Salt Disposition Alternatives Identification Preconceptual Phase I Summary.

15. HLW-SDT-980014, Position Paper on Dispositioning of Pro-Formas Received During Phase II.

16. HLW-SDT-980004, Position Paper on Determination of Risk and Risk Handling Strategies for the Initial List Alternatives. 


\section{$\underline{17.0 \quad \text { References (continued) }}$}

17. Trip Report - Site Visited: Hanford; May 22, 1998; L. Papouchado, E. Kosiancic, J. Carlson, P. Suggs (DOE).

18. Trip Report - Site Visited: West Valley Site; June 1, 1998; K. Rueter (WSRC), E. Murphy (WSRC), P. Suggs (DOE).

19. Trip Report - Sites Visited: Willowcreek (INEEL), ICPP (INEEL); May 11, 1998; L. Papouchado, E. Kosiancic, J. Carlson, P. Suggs (DOE).

20. Trip Report - Site Visited: Oak Ridge National Laboratory; May 31, 1998; K. Rueter, P. Hudson, E. Murphy, P. Suggs (DOE).

21. Trip Report - Site Visited: Sellafield; June 2, 1998; S. Piccolo (WSRC), K. Rueter (WSRC), P. Hudson (BNFL), J. Barnes (WSRC), B. Spader (DOE).

22. HLW-SDT-980010, Position Paper on the Approach to Information Handling, Analysis and Reporting.

23. HLW-SDT-980009, Position Paper on the Approach to Flowsheet Analysis.

24. HLW-SDT-980013, Position Paper on Life Cycle Cost Analysis to Select the Short List of Alternatives.

25. HLW-SDT-980006, Position Paper on the Definition and Utilization of Weighted Evaluation Criteria to Select the Short List of Alternatives.

26. HLW-SDT-980012, Results of the HLW Salt Disposition Systems Engineering Team Phase II Criteria Selection and Weighting for HLW Salt Disposition "Initial List" Down Selection.

27. WSRC-TR-98-00236, Sensitivity Analyses of Alternative Methods for Disposition of High Level Salt Waste: A Position Statement (U).

28. WSRC-TR-98-00240, Results Report on Sensitivity Analysis for Initial List Alternatives.

29. HLW-SDT-980005, Position Paper on Identifying \& Documenting Dissenting Opinions in the Evaluation and Selection of Alternatives to the In-Tank Precipitation Process 


\subsection{References (continued)}

30. DOE/NE/44139-25, Selection of the Treatment Method for the West Valley Alkaline Supernatant (1987)

31. ORNL/TM-13503, Cesium Removal Demonstration Utilizing Crystalline Silicotitanate Sorbent for Processing Melton Valley Storage Tank Supernate: Final Report (1998)

32. Evaluation and Testing of Inorganic Ion Exchange Sorbents for the Removal of Cesium137 from Idaho Chemical Processing Plant Acidic Tank Wastes (unpublished) (1998)

33. SD-WM-ES-023, Evaluation of Process and Facility Options for Treatment of DoubleShell Tank Wastes (1983)

34. Position Paper on Identifying Alternatives to the In-Tank Precipitation Process. 


\subsection{List of Abbreviations and Acronyms}

The following abbreviations are used through the report and are listed for clarification.

1. $\mathbf{A B}$ - Authorization Basis

2. AMP - ammonium molybdophosphate

3. BNFL - British Nuclear Fuels plc

4. Ci - Curie

5. CIF - Consolidated Incineration Facility

6. Cs - cesium

7. $\mathbf{C S T}$ - crystalline silicotitanate

8. D\&D - Decontamination and Decommission

9. df - decontamination factor

10. DNFSB - Defense Nuclear Facilities Safety Board

11. DOE - Department of Energy

12. DWPF - Defense Waste Processing Facility

13. EARP - Enhanced Actinide Removal Plant

14. EPA - Environmental Protection Agency

15. ESP - Extended Sludge Processing

16. ETF - Effluent Treatment Facility

17. FFA - Federal Facility Agreement

18. gr - gram

19. HIC - High Integrity Container

20. HLW - High Level Waste 


\subsection{List of Abbreviations and Acronyms (continued)}

20. INEEL - Idaho National Engineering and Environmental Laboratory

21. ISMS - Integrated Safety Management System

22. ITP - In-Tank Precipitation

23. IWP - Integrated Work Process

24. KASE - Key Activities for Successful Execution

25. LCC - Life Cycle Cost

26. LDR - Land Disposal Restricted

27. MAUA - Multi-Attribute Utility Analysis

29. $\mathbf{N a O H}$ - Sodium Hydroxide

30. NaTPB - sodium tetraphenylborate

31. $\mathbf{N H}_{4}{ }^{+}$- ammonium

32. NHC - Numatec Hanford Company

33. $\mathbf{N O}_{\mathbf{x}}$ - Oxides of Nitrogen

34. NTS - Nevada Test Site

35. O\&M - Operation and Maintenance

36. OPC - Other Project Cost

37. ORNL - Oak Ridge National Laboratory

38. PAN - Polyacrylonitrile

39. PFD - Process Flow Diagram

40. plc - public limited company

41. PNNL - Pacific Northwest National Laboratory 


\subsection{List of Abbreviations and Acronyms (continued)}

42. PTA - Phosphotungstic Acid

43. RAMI - Reliability, Availability, Maintainability, and Inspectability

43. $\quad \mathbf{R F}-$ resorcinol formaldehyde

44. SCDHEC - South Carolina Department of Health and Environmental Control

45. SEMP - Systems Engineering Management Plan

46. SIXEP - Site Ion Exchange Plant

47. $\mathbf{S r}-$ Strontium

48. SRS - Savannah River Site

49. SRTC - Savannah River Technology Center

50. STP - Site Treatment Plan

51. Team - HLW Salt Disposition Systems Engineering Team

52. TEC - Total Estimated Cost

53. THORP - Thermal Oxide Reprocessing Plant

54. TPB - tetraphenylborate

55. TPC - total project cost

56. TRU - transuranic

57. TWRS - Tank Waste Remediation System

58. UF - Utility Function

59. WEP - Waste Encapsulation Plant

60. WPEP - Waste Packaging and Encapsulation Plant

61. WSMS - Westinghouse Safety Management Solutions, Inc. 


\subsection{List of Abbreviations and Acronyms (continued)}

62. WSRC - Westinghouse Savannah River Company

63. WVDA - West Valley Demonstration Act

64. WVNS - West Valley Nuclear Services

65. WVP - Windscale Vitrification Plant 